\title{
PERFORMANCE OF UPHC FILLED STEEL COLUMN
}

\author{
By \\ Navneet Singh \\ Beach, GZS College, Bathinda, Punjab, India 2016 \\ An MRP \\ presented to Ryerson University \\ in partial fulfillment of the \\ requirements for the degree of \\ Master of Engineering \\ In the program of \\ Civil Engineering
}

Toronto, Ontario, Canada, 2019

(C) Navneet Singh, 2019 


\section{Author's declaration}

I hereby declare that I am the sole author of this thesis project. This is a true copy of the MRP, including any required final revisions.

I authorize Ryerson University to lend this MRP to other institutions or individuals for the purpose of scholarly research.

I further authorize Ryerson University to reproduce this MRP by photocopying or by other means, in total or in part, at the request of other institutions or individuals for the purpose of scholarly research.

I understand that my thesis project will be made available electronically to the public. 


\title{
Abstract \\ Performance of UHPC Filled Steel Columns
}

\author{
By \\ Navneet Singh \\ Master of Engineering \\ Civil Engineering \\ Ryerson University, Toronto, Canada, 2019
}

Ever since the development of the Ultra-High-Performance Concrete [UHPC], research has been going on in the use of hollow steel tubes filled with UHPC as a super-frame structural member. The key area of this research is to study the influence of confinement effect on the behavior of the Super-frame column and to develop guidelines in modern codes for the design of such composite sections. This project report compares the performance UHPC filled steel tubes and conventional sections using a computer program, Lab experiment and analytical analysis. The results of all the analysis show that UHPC filled tubes perform better than the conventional sections such as only steel sections or concrete sections. Additionally, Eurocode - 4 predicts reasonable results. 


\section{Acknowledgments}

At first, I feel thankful to my Supervisor Dr. Hesham Marzouk for giving me this opportunity and whose valuable guidance helped me to complete the project and have insight knowledge of research work I did.

Secondly, I would like to thank Dr. Hesham Othman for his immense support throughout the project. I feel grateful to him for his assistance in analysis and experimental work. He was always available for whatever problem I faced in the project and helped me to get through them.

I appreciate the help I got from Nidal Jaalouk, Khaleel Stoney and other lab assistants. Their experience and knowledge in setting up for the tests are greatly appreciated.

A special thank goes to my colleagues, Youssef Hilal and Jamil Madanat who were my helping hands throughout.

Last but not least, I am thankful to Ryerson University for providing me the opportunity to contribute to this research and be useful to the field of civil engineering. 


\section{Dedication}

I want to dedicate this project to my family, friends and especially my brother Sargam who always appreciated and showed faith in me. The support of all of them helped me to complete this project successfully. 


\section{Table of contents}

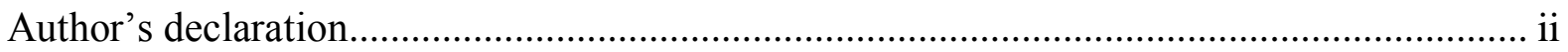

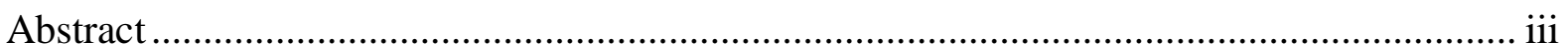

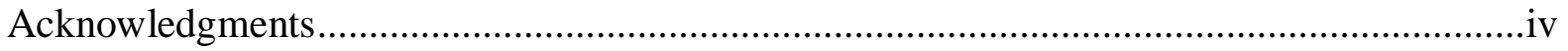

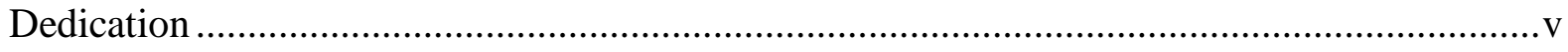

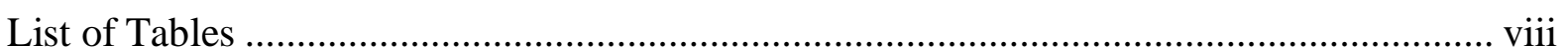

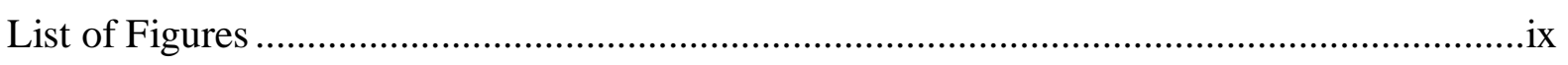

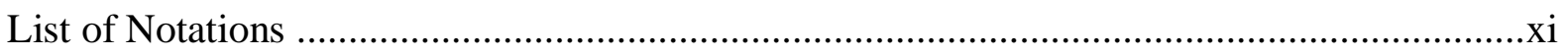

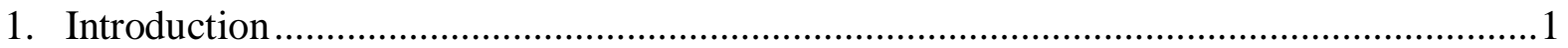

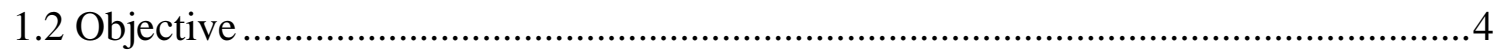

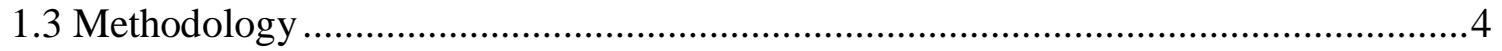

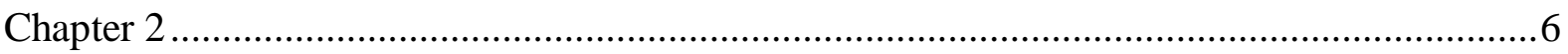

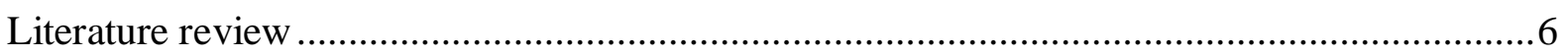

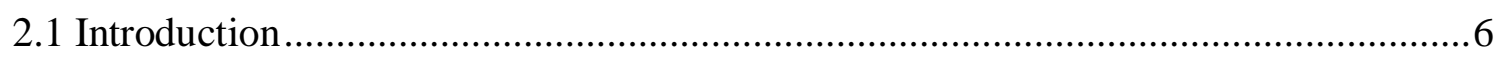

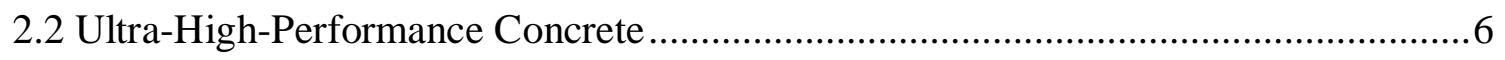

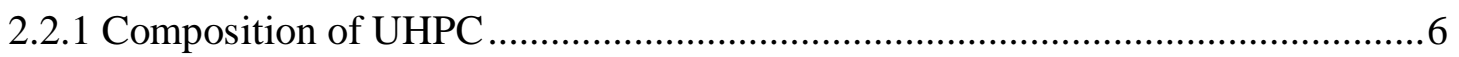

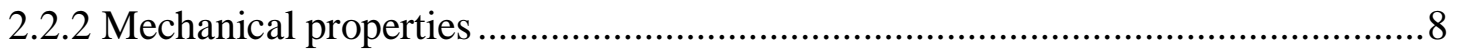

2.2.3 Dynamic and Impact Performance of UHPC..................................................

2.2.4 Effect of fibers .......................................................................................... 11

2.2.5 Structural Behavior of Confined UHPC Columns ............................................ 12

2.2.6 Challenges for the use of UHPC ................................................................. 18

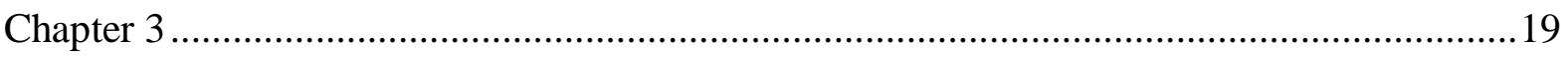

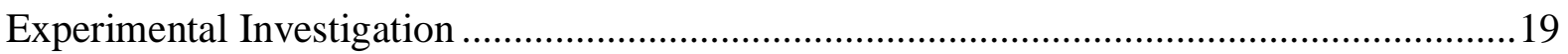

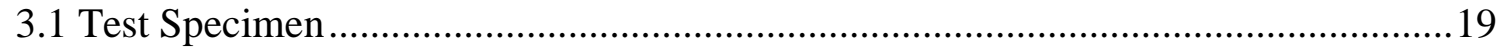

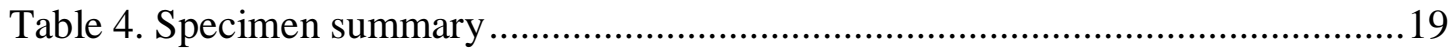

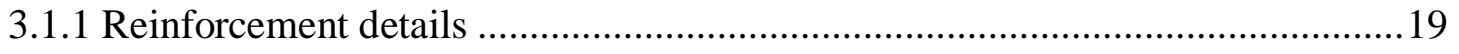

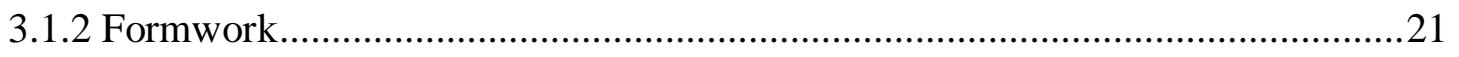

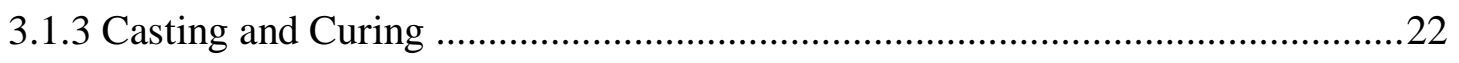

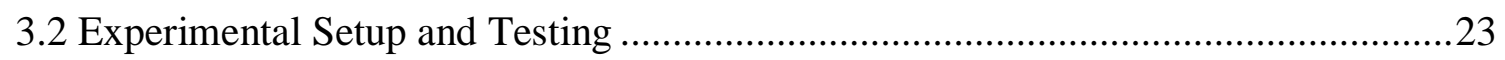

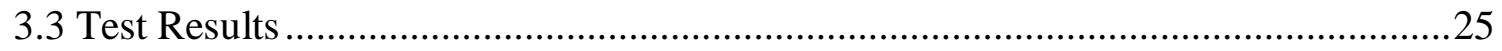

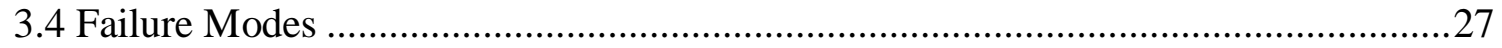

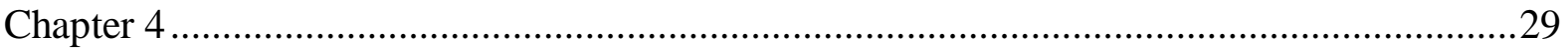

Analytical approach of Composite Steel/UHPC section .....................................................29

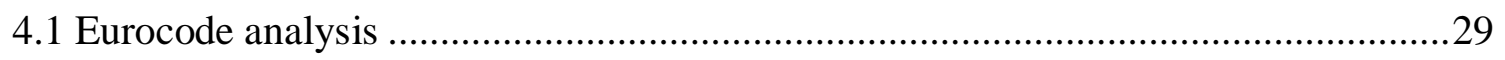

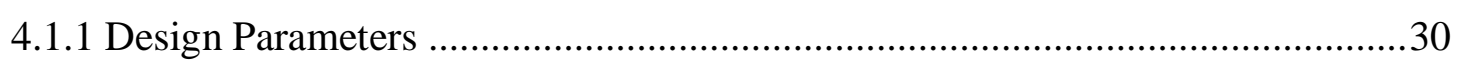

4.1.2 Column - Interaction Diagram Procedure ..................................................... 30 


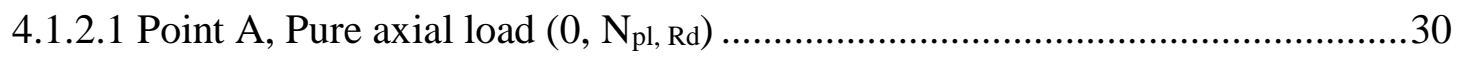

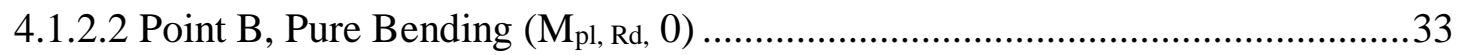

4.1.2.3 Point $\mathrm{C}$, Prior to yielding of steel......................................................................

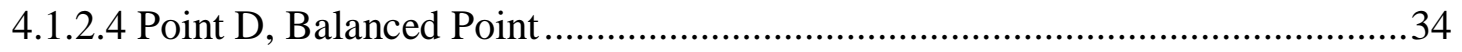

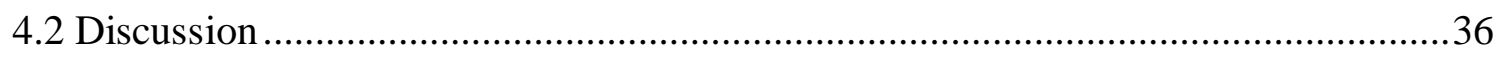

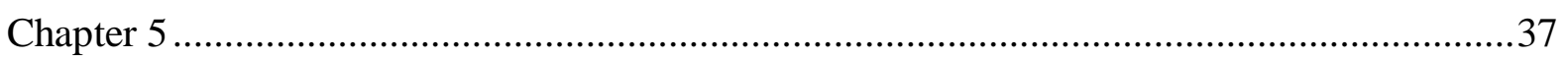

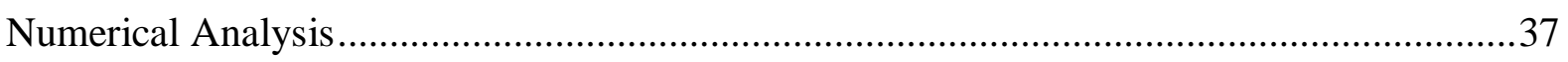

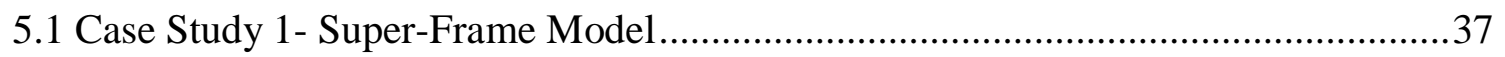

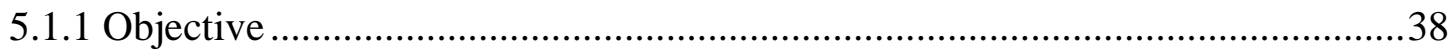

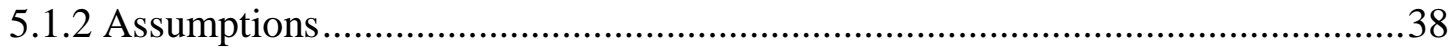

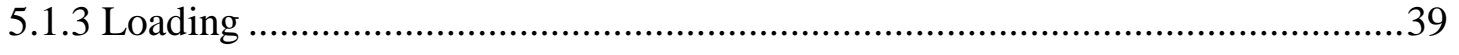

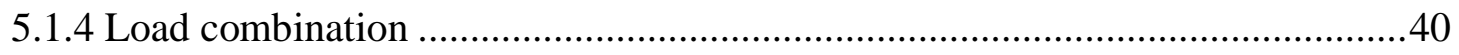

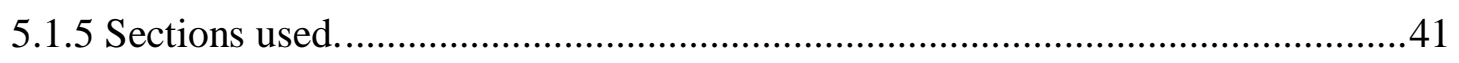

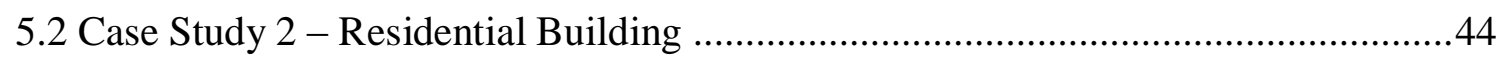

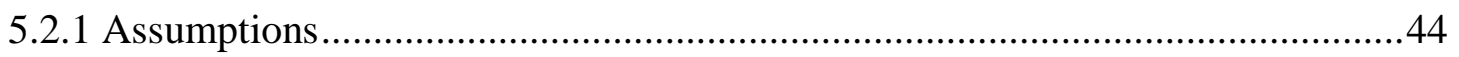

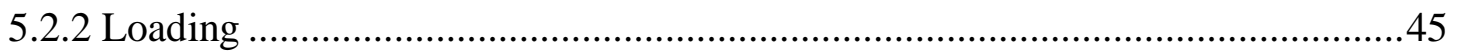

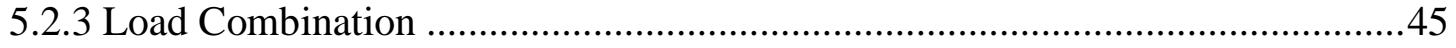

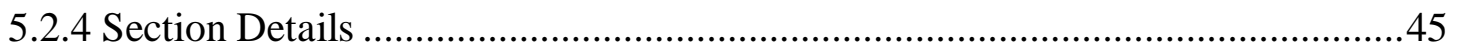

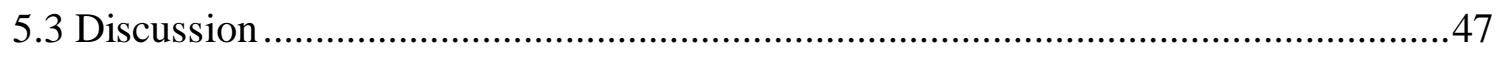

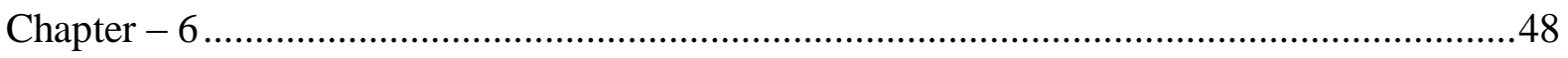

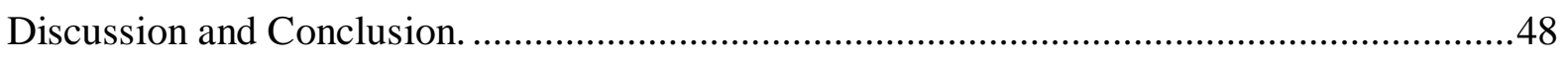

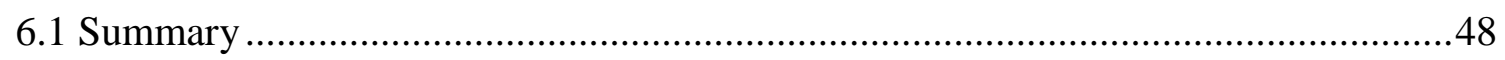

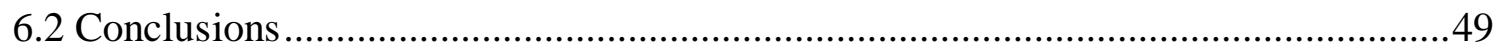

6.2.1 Experimental testing conclusions .................................................................49

6.2.2 Analytical model calibration conclusion ......................................................49

6.2.3 Numerical comparative study conclusions ...................................................49

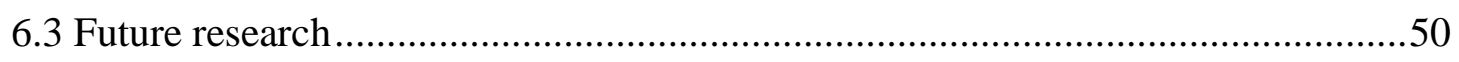

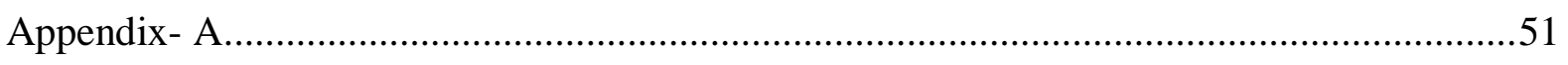

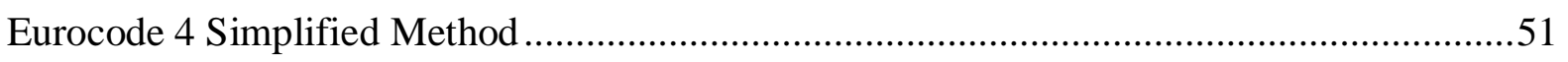

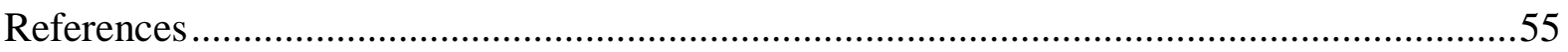




\section{List of Tables}

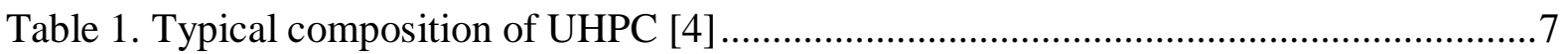

Table 2. Typical mechanical properties of UHPC [4] .....................................................

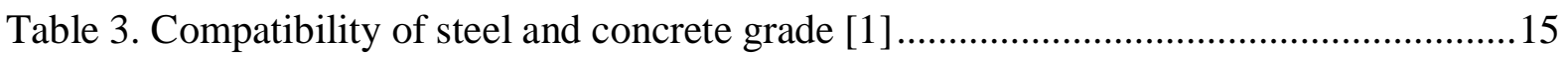

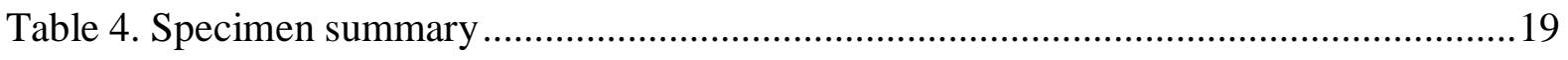

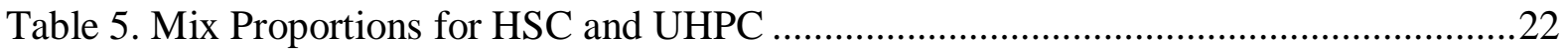

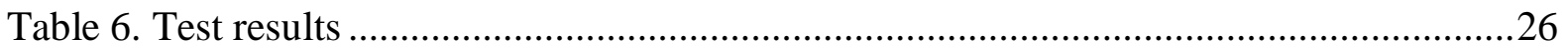

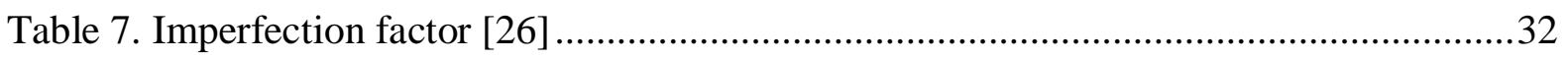

Table 8. Column Interaction Point for UHPC. ............................................................... 34

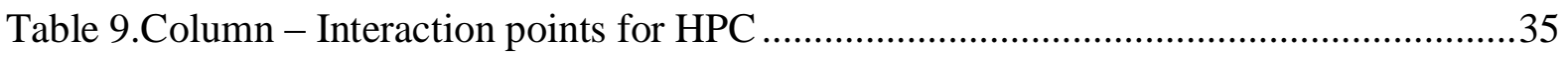

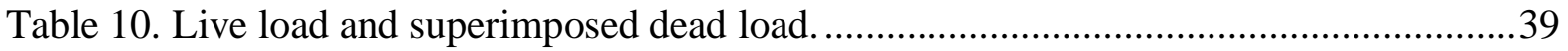

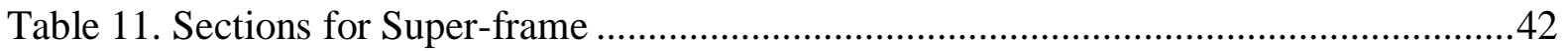

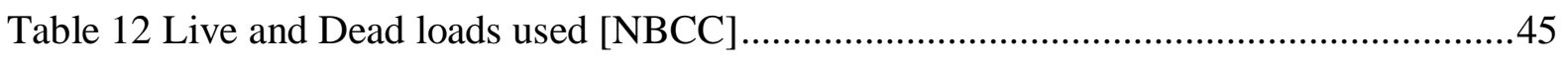

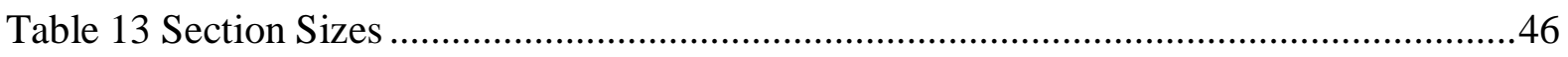




\section{List of Figures}

Figure 1. Techna Station, Tokyo, Japan utilizing UHPC Filled CFST Columns [1] ...............2

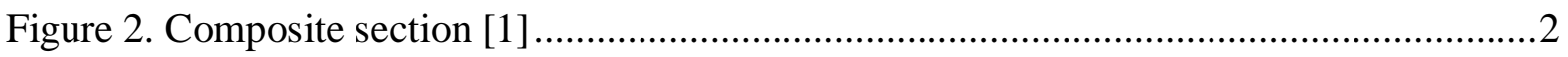

Figure 3. Super-frame with mega Composite column [1] ................................................

Figure 4. Comparison of UHPC and NSC a): compressive strength, [9] .............................

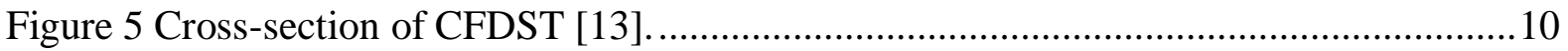

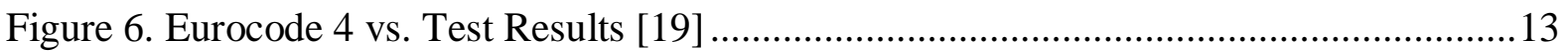

Figure 7. Schematic setup (left), Actual setup ( right) [1] ...............................................13

Figure 8. Table showing test results for concentric loaded column [1] ............................... 14

Figure 9. Table showing test result for eccentrically loaded column [1] .............................14

Figure 10. Effect of increasing both concrete and steel strengths [1] ................................ 15

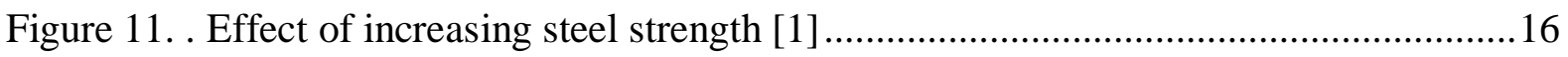

Figure 12. Effect of increasing concrete strength [1] .................................................. 16

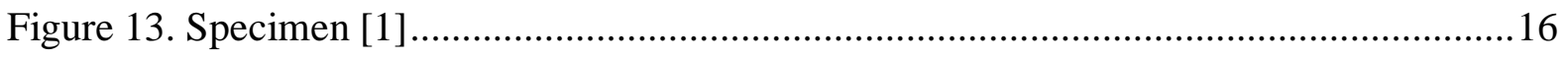

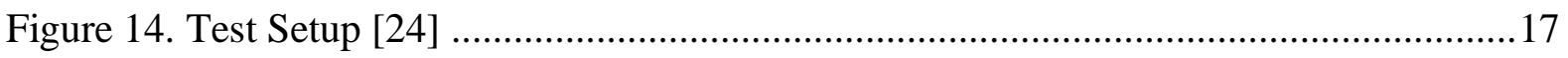

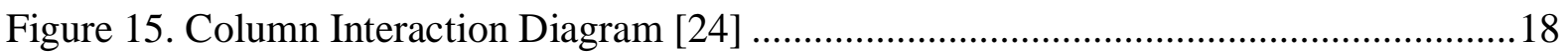

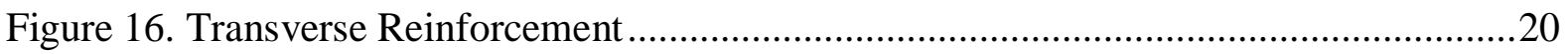

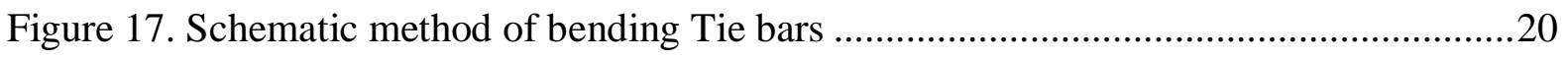

Figure 18. Binding tie bars and longitudinal bars using zip ties........................................21

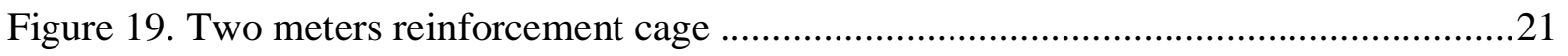

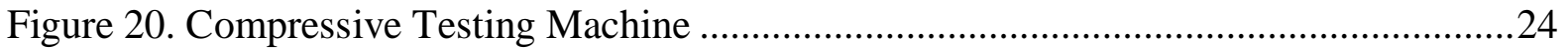

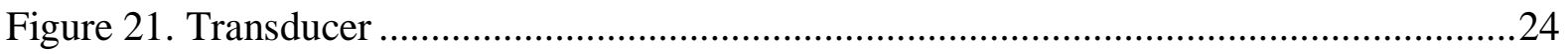

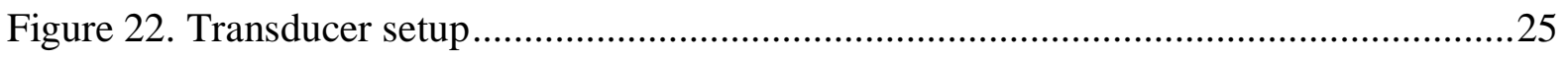

Figure 23. load vs. axial deformation of Unconfined HPC and UHPC specimens ................26

Figure 24. load vs. axial deformation of confined HPC and UHPC specimens ....................27 
Figure 25. Failure modes of Unconfined UHPC and HSC ..............................................28

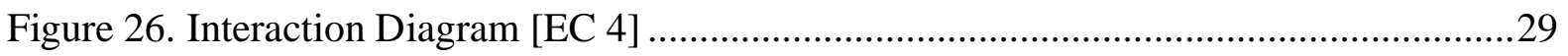

Figure 27. Column - Interaction Diagram for confined UHPC and HPC ..............................35

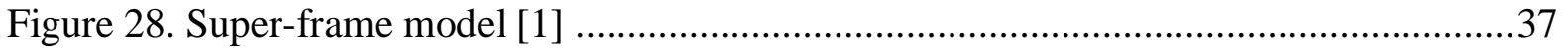

Figure 29. Super-frame Elevation and Plan (dimensions are in Meters) ...............................38

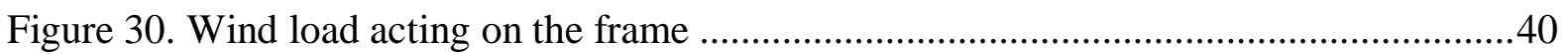

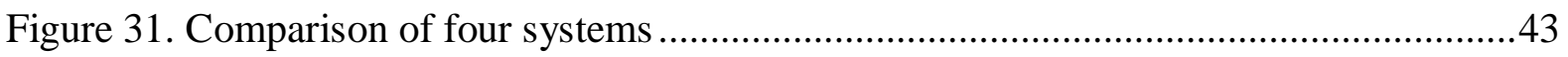

Figure 32. Building plan and Elevation (Meters) ........................................................44

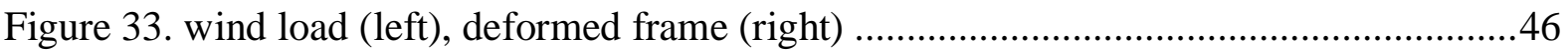

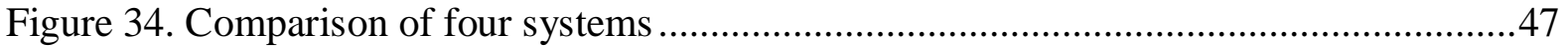




\section{List of Notations}

\begin{tabular}{|c|c|}
\hline CFST & Concrete Filled Steel Tube \\
\hline UHPC & Ultra-High-Performance Concrete \\
\hline EC 4 & Eurocode 4 \\
\hline HSC & High Strength Concrete \\
\hline SCM & Supplementary Cementitious Materials \\
\hline ITZ & Interfacial Transition Zone \\
\hline CFST & Concrete filled steel tube \\
\hline NSC & Normal Strength Concrete \\
\hline UHP-FRC & Ultra-High-Performance Fiber Reinforced Concrete \\
\hline$P_{r}$ & Axial Load Capacity of column \\
\hline$\alpha_{1}$ & $\begin{array}{l}\text { Mathematical parameter of equal compression for stress } \\
\text { distribution }\end{array}$ \\
\hline$\phi_{C}$ & Strength reduction factor for concrete \\
\hline$f^{\prime}{ }_{C}$ & Specified compressive strength for concrete \\
\hline$A_{g}$ & Gross area of the specimen \\
\hline$f_{y}$ & Yield strength of steel \\
\hline$A_{s t}$ & Area of reinforcement \\
\hline$\eta$ & Reduction factor for concrete strength higher than $90 \mathrm{MPa}$ \\
\hline$E_{c m}$ & Modified secant modulus of concrete \\
\hline$f_{c k}$ & Characteristic strength of concrete \\
\hline$\chi$ & Buckling reduction factor \\
\hline$\rho$ & Percentage of reinforcement \\
\hline
\end{tabular}




\begin{tabular}{|c|c|}
\hline $\mathrm{N}_{p l, R k}$ & the characteristic value of the plastic resistance to compression \\
\hline $\mathrm{N}_{c r}$ & Euler Buckling resistance \\
\hline El & Flexural stiffness \\
\hline $\mathrm{A}_{a}$ & Area of steel tube \\
\hline $\mathrm{A}_{C}$ & Area of concrete \\
\hline $\mathrm{A}_{S}$ & Area of steel reinforcement \\
\hline $\mathrm{E}_{a}$ & Modulus of Elasticity of Steel \\
\hline $\mathrm{E}_{S}$ & Modulus of Elasticity of Steel \\
\hline $\mathrm{I}_{a}$ & Moment of inertia of steel tube \\
\hline $\mathrm{I}_{s}$ & Moment of inertia of steel reinforcement taken as steel tube \\
\hline $\mathrm{I}_{c}$ & Moment of inertia of concrete \\
\hline $\mathrm{h}_{n}$ & Depth of neutral axis \\
\hline $\mathrm{f}_{c d}$ & Specified strength of concrete \\
\hline $\mathrm{f}_{y d}$ & Yield strength of steel tube \\
\hline $\mathrm{f}_{s d}$ & Yield strength of steel reinforcement \\
\hline $\mathrm{t}_{\text {tube }}$ & Thickness of steel tube \\
\hline $\mathrm{t}_{s}$ & Equivalent thickness of reinforcement converted to the steel tube \\
\hline $\mathrm{M}_{p l, R d}$ & plastic bending resistance given by Point $B$ \\
\hline$W_{p c}$ & Plastic section modulus of concrete section \\
\hline$W_{p c, n}$ & Plastic section modulus of concrete section relative to neutral axis \\
\hline$W_{p a}$ & Plastic section modulus of structural steel section \\
\hline$W_{p a, n}$ & $\begin{array}{l}\text { Plastic section modulus of reinforcement section relative to the } \\
\text { neutral axis }\end{array}$ \\
\hline$W_{p s}$ & Plastic section modulus of reinforcement \\
\hline
\end{tabular}


$W_{p s, n}$

$N_{p m, R d}$

$N_{D R}$
Plastic section modulus of reinforcement relative to neutral axis Design resistance to compression of a CFST column prior to steel yielding

Design resistance to compression of a CFST column at balance load 


\section{Chapter 1}

\section{Introduction}

The use of Ultra-High-Performance Concrete (UHPC) offers more economical and architectural advantages and are gaining demand in high rise building construction. With the use of UHPC, the section sizes can be reduced for high rise buildings this, in turn, saves material and money. With the use of UHPC more floor space can be used by having longer spans and high columns. The dense microstructure of UHPC makes it more resistant to the attack of chemical and physical agents and thus improves the durability and lifespan of the structure. Low shrinkage of UHPC makes it good non-shrink grout material. UHPC permits the design of thinner concrete sections, this enhances the architectural beauty of the structures, and more random shaped structures can be built. UHPC offers much more enhanced mechanical properties, low shrinkage and creep characteristics. One of the main concerns for the use of UHPC material is to examine its brittleness and local buckling behavior of a composite steel section with a concrete core. The solution to this problem can be the use of composite sections, mainly steel hollow tubes filled with UHPC. With the introduction of Concrete Filled Steel Tube (CFST) filled with UHPC, many architectural and economic benefits can be achieved. UHPC permits the use of slenderer column that reduce the amount of concrete and provide more space in the building. In the composite sections, brittleness of concrete is overcome by the confinement effect of the steel and the local buckling of the steel is prevented by the concrete core. Figure 1 shows a Techna Station building in Japan made by using UHPC filled CFST columns [1]. 


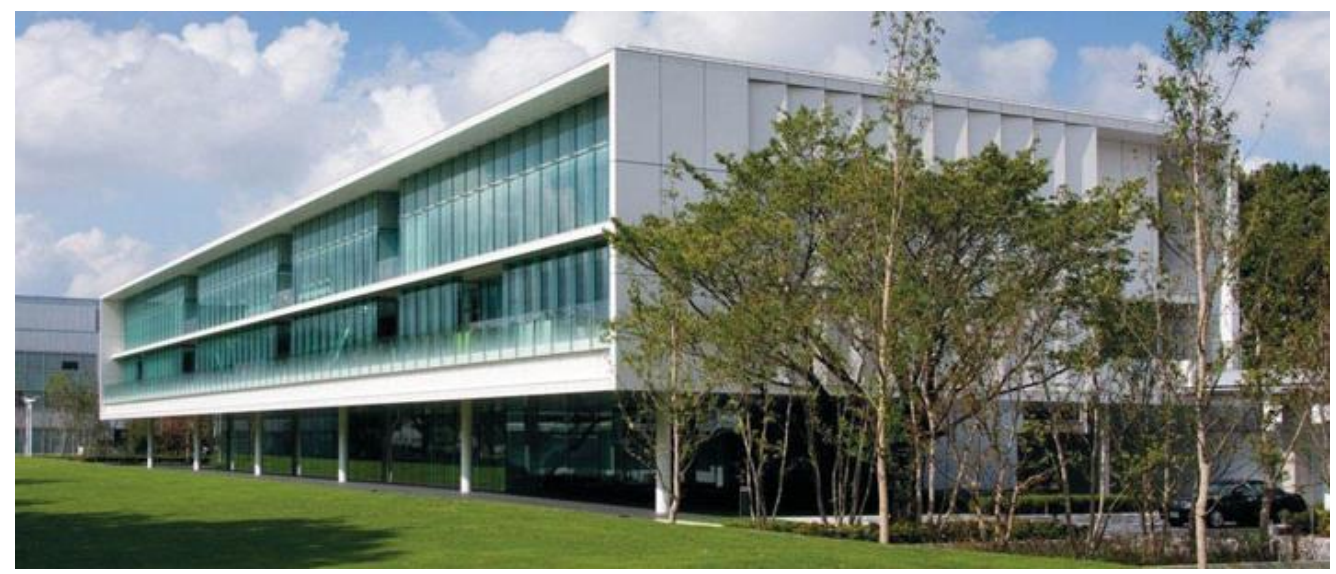

Figure 1. Techna Station, Tokyo, Japan utilizing UHPC Filled CFST Columns [1]

CFST column, are widely used for high rise buildings. Hollow steel tube act as a permanent formwork thus it enables faster construction. Figure 2 shows some of the widely used composite section.
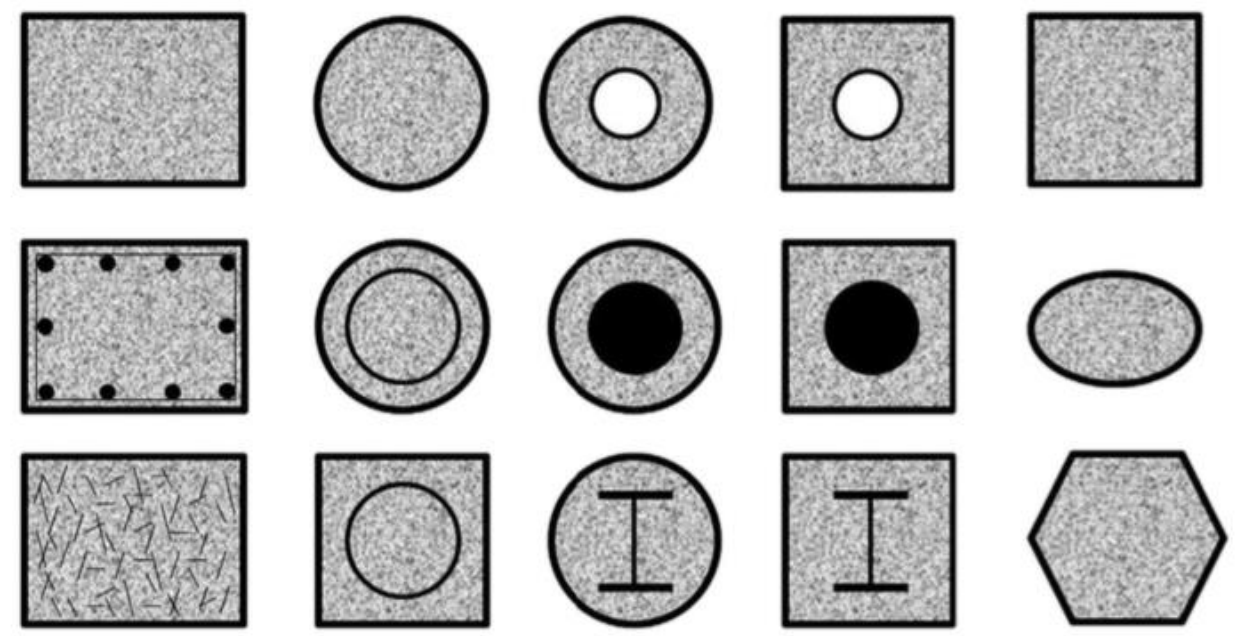

Figure 2. Composite section [1]

Some of the key advantages of the composite section are :

$>$ The reduction in section size could saves million dollars' worth of material.

$>$ Composite sections provide more resistance to impact loads [14].

$>$ With no requirement of formwork, the construction time would reduce considerably. 
$>$ Encasing with steel would protect the concrete from corrosion and other attacking agents.

\subsection{Scope}

The scope of the research is to determine the axial capacity and lateral stiffness of UHPC-filled steel tube columns in comparison to steel and concrete sections for Super-frames. The application of CFST columns is to have Mega column extending 7-8 stories then an outrigger truss system. The Mega column known as Super-frame acts as a main resisting system with secondary infilled frames that act to transfer the vertical loads. These types of structures are mainly used for industrial purposes where large equipment is to be installed. In structures like that large clear space is required which implies that large span columns of 15 to $20 \mathrm{~m}$ height. Traditional construction materials cannot be used to make such high slender columns. The use of the only UHPC to cast such columns can lead to failure due to buckling because of such slender columns. The second approach would be the use of composite steel sections. The problem with that is due to large height huge sections would be required, which will lead to a tremendous increase in the cost of the structure making it uneconomical and less internal space. The solution to this problem is the use of composite sections made of hollow steel tubes filled with UHPC. The confinement effect of steel would prevent the local buckling of concrete, and the UHPC would permit the use of a smaller steel section. Therefore, subsiding the cost of construction. Figure 3 shows the mechanism of the idealization of the Super-frame system. The main load-bearing system consists of Mega Column made of composite UHPC filled steel tubes extending 5 to 6 stories followed by an outrigger system. The inner space can have left free for machines or can be filled with an inner frame that will help in carrying vertical loads thus the system can be used for residential or office purposes as well. 


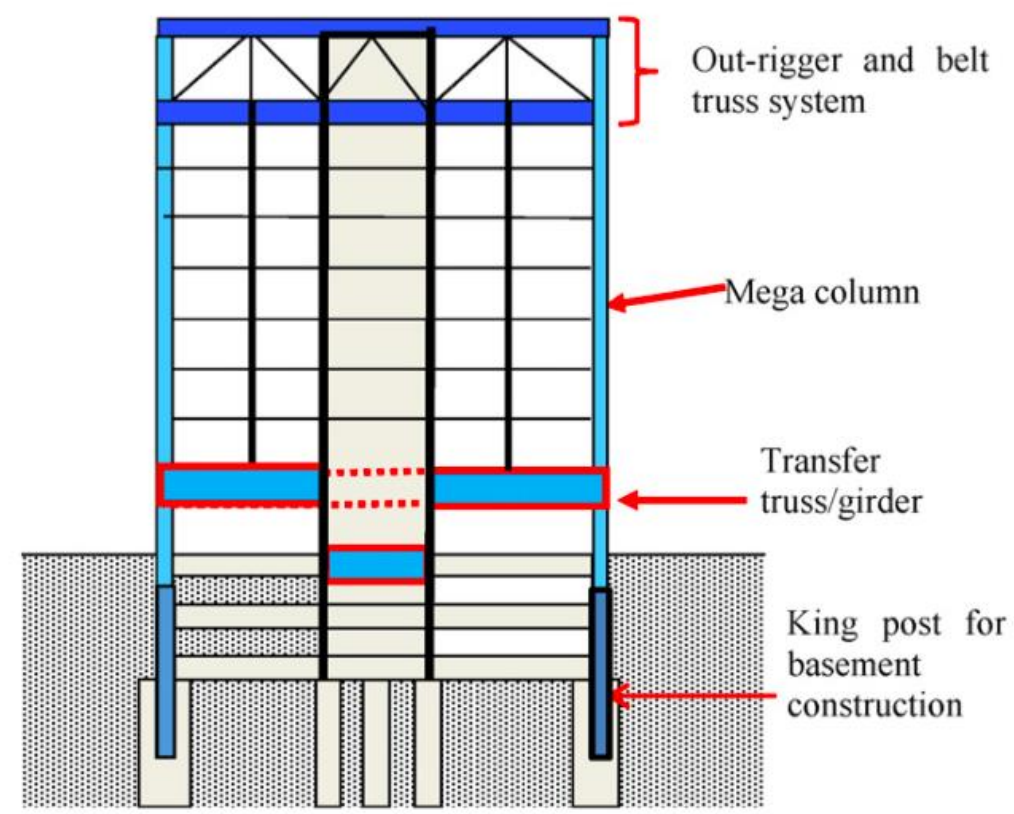

Figure 3. Super-frame with mega Composite column [1]

\subsection{Objective}

The objective of the study is to

Compare the performance of a multi-story structure using UHPC filled columns to conventional frames by assessment of lateral drift using a computer program.

Develop column interaction curves using acceptable analytical methods.

Examine the effectiveness of the use of the Super-frame from the structural stability point of view for the high-rise construction.

\subsection{Methodology}

An experimental study was conducted based on the past research work conducted on steel tube filled UHPC. Two-meter columns were cast to examine the performance under practical loads and have valid data. Lateral numerical sway analysis using ETABS was also developed to see the performance of four different systems against lateral wind loading.

\section{Steel Columns}


$>$ UHPC Columns

UHPC Filled Steel Tube Columns

$>$ Braced frame

Also, an analytical model based on the equilibrium and compatibility equations will be used to develop the column interaction diagram of the Super-frame column. Column Interaction Diagram using Euro-code 4 simplified approach by accounting for the effect of buckling was made to see the comparison of UHPC sections against HSC. 


\section{Chapter 2}

\section{Literature review}

\subsection{Introduction}

The use of high strength construction materials offers more economical and architectural advantages and are gaining demand in high rise building construction. With the use of high strength, the section sizes can be reduced for high rise buildings this, in turn, saves material and money. With the development of UHPC research has been going on from years to make steel tube filled with UHPC sections. These sections are expected to perform way better than conventional sections. A lot of studies have been performed to study the effect of the confinement effect of steel tubes on structural behavior and development of design guides accordingly in the modern codes which do not cover this modern approach known as superstructure frame without the use of the standard lateral steel bracing. This literature review discusses some of the research work done in this field

\subsection{Ultra-High-Performance Concrete}

Ultra-high-performance concrete also known as reactive powder concrete (RPC) which is made by combining Portland cement, SCM, fine sand, superplasticizers, admixtures, and water. Due to the presence of very fine particles, the microstructure of UHPC is very dense with smooth surface finish [2].

\subsubsection{Composition of UHPC}

Typical composition of UHPC consists of very low water/cement of about less than 0.25 and containing at least $20 \%$ micro-silica fume having a carbon content of less than $0.5 \%$ [3]. In this study UHPC used is obtained from Ductal ${ }^{\circledR}$ by Lafarge North America. Typical composition of the Ductal® with $2 \%$ short straight steel fibers is given in Table 1 . 
Table 1. Typical composition of UHPC [4]

\begin{tabular}{|c|c|c|}
\hline Material & $\begin{array}{c}\text { Bulk density } \\
\left(\mathrm{kg} / \mathrm{m}^{3}\right)\end{array}$ & $\begin{array}{c}\text { Percent by } \\
\text { weight }(\%)\end{array}$ \\
\hline Portland cement & 712 & 28.5 \\
\hline Fine sand (size $<0.5 \mathrm{~mm})$ & 1020 & 40.8 \\
\hline Silica fume & 231 & 9.3 \\
\hline Ground quartz & 211 & 8.4 \\
\hline Superplasticizer & 30.7 & 1.2 \\
\hline Accelerator & 30 & 1.2 \\
\hline Steel fibres & 156 & 6.2 \\
\hline Water & 109 & 4.4 \\
\hline
\end{tabular}

\subsubsection{Binders and water/binder ratio}

Water binder ratio for UHPC ranges from 0.16 to 0.27 with 0.22 being the optimum amount. For producing UHPC, it is preferable to use cement with low $\mathrm{C}_{3} \mathrm{~A}$ specific area, higher $\mathrm{C}_{3} \mathrm{~A} \mathrm{SO}^{2-}{ }_{4}$ ratio and alkali content [3]. The typical water/binder ratio for UHPC is less than $0.25[5]$.

\subsubsection{Aggregates}

The study shows that failure in concrete is mainly governed by damage at ITZ between cement paste and aggregates [2]. Therefore, to produce UHPC, coarse aggregates are eliminated. The use of more fine particles like quartz, silica fume in UHPC also reduces the thickness of the paste that plays a key role in UHPC mix design. For quartz particles of size $0.8 \mathrm{~mm}$, optimum sand to cement ratio of 1.4 was found [3].

\subsubsection{Workability}

The major problem with the UHPC is that its handling is difficult because of the very low W/B ratio. The presence of the steel fibers also affects the workability. Increasing the fiber content decreases the workability so an optimum limit for the dosage of the fibers should be found. The workability of UHPC with fiber dosage greater than $2.5 \%$ is low [6]. UHPC having fibers 
of small aspect ratio are more workable than mixes containing fibers with larger aspect ratio even for a high dosage of fibers. $6 \mathrm{~mm}$ long and 0.15 diameter fibers can use up to $10 \%$ while $12 \mathrm{~mm}$ and $0.15 \mathrm{~mm}$ dia fibers can be used up to $3 \%$ by volume of the mixture without degrading the workability of the mix [3].

\subsubsection{Mechanical properties}

The studies found that the curing methods play a key role in mechanical properties of UHPC. The best curing technique for UHPC is a heat curing that could produce a 28-day compressive strength of $196 \mathrm{MPa}$. Steam curing is also a good alternative, but it mainly enhances the early age strength [7]. Flexure strength of up to $48 \mathrm{MPa}$ has been reported from previous research work [8]. The experimental study conducted at the Department of Civil and Environmental Engineering, Florida evaluates the mechanical properties of UHPC by the cylinder and cube testing and also provide FE program to compare the results. UHPC was obtained from Ductal® containing $2 \%$ by volume of steel fibers. The test results show that the compressive strength of UHPC was about $(3-4)$ times greater than normal concrete. The modulus of elasticity of UHPC was found double than normal concrete representing higher ductility of UHPC. The strong interlocking bond between the fibers and concrete matrix prevented the spalling of UHPC into pieces, and it also imparted higher tensile strength and ductility in the range of $2-$

4 times greater than the normal concrete [9]. a) Compressive strength

b) Tensile strength

Figure 4 shows the comparison of compressive strength and tensile strength of UHPC and NSC [9]. 


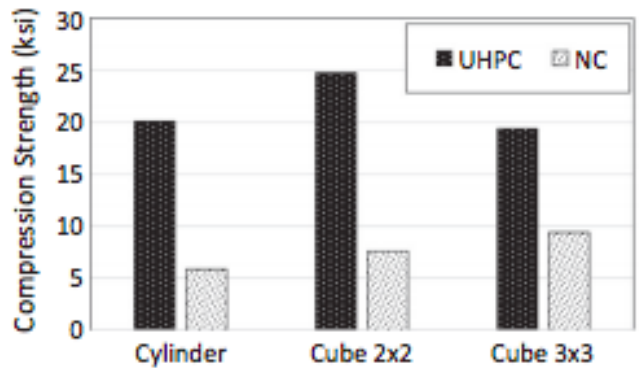

a)

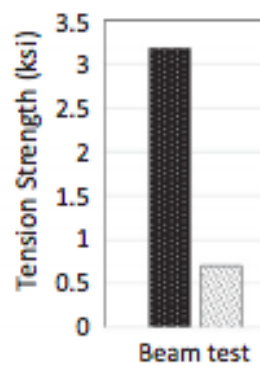

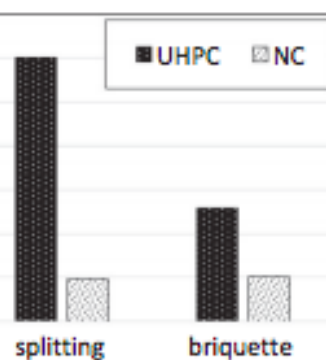

b)

a) Compressive strength

b) Tensile strength

Figure 4. Comparison of UHPC and NSC [9]

The enhanced mechanical and durability properties of UHPC makes it a better option in comparison to conventional concrete. UHPC in addition to its high compressive strength of more than $150 \mathrm{MPa}$ [3] offers many more beneficial mechanical properties like high tensile strength, high modulus of elasticity, strain hardening behavior [10]. Regarding durability, UHPC offers more resistance to corrosion, abrasion and other chemical agents [11]. In this study, UHPC used is Ductal® specified by Lafarge North America [12]. The typical mechanical properties of the Ductal® UHP-FRC are given in Table 2.

Table 2. Typical mechanical properties of UHPC [4]

\begin{tabular}{|l|l|}
\hline Mechanical Properties & Range \\
\hline Compressive strength & $150-200 \mathrm{MPa}$ \\
\hline Direct Tensile Strength & $8-15 \mathrm{MPa}$ \\
\hline Flexural strength & $30-40 \mathrm{MPa}$ \\
\hline Elastic Modulus & $45-55 \mathrm{GPa}$ \\
\hline Poisson's ratio & 0.2 \\
\hline Density & $2,500 \mathrm{Kg} / \mathrm{m}^{3}$ \\
\hline
\end{tabular}

\subsubsection{Dynamic and Impact Performance of UHPC}


A research team at School of Civil Engineering, Southeast University, China conducted an experimental study on CFDST Columns exposed to contact explosion using TNT explosive. The experimental results show that CFDST columns had an only local failure while the whole column remained intact. The concrete core absorbed a significant amount of blast energy. The study reveals that CFDST columns offer two main advantages. One is the confined concrete core absorbs blast energy thereby lowering the damage, another is the outer steel tube prevents the spalling of concrete thus making the column stand still even after damage has been done to the concrete core [13]. Figure 5Figure 5 shows the cross-section of CFDST.

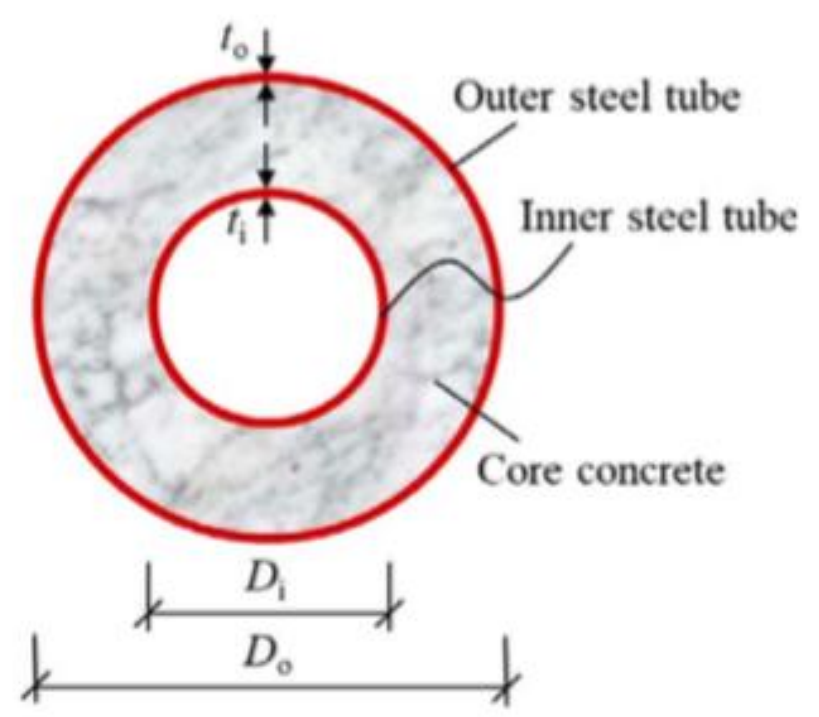

Figure 5 Cross-section of CFDST [13].

An experimental study was conducted to investigate the performance of UHPC in impact resistance structure [14]. The test results show that the performance of UHPC plates was much superior in comparison to reinforced HSC concrete plates under low-velocity impact loading. The impact capacity of UHPC plates was 2.3 to 6.4 times the capacity of HSC plate. With the use of the UHPC, the failure mode was changed to pure flexural instead of punching failure. 
With the increase in the fiber content to $3 \%$ and steel reinforcement ratio improves the dynamic properties of UHPC plates [14].

The impact damage capacity of UHPC was evaluated using repeated low-velocity impact and forced vibration tests. Test results show that the damage rate of UHPC plates was in the order of 6 to $15 \%$ of NSC plates. UHPC plates had more impact capacity and showed ductile failure in comparison to HSC and NSC plates that failed suddenly. Increasing the fiber content have a positive effect on the damage control behavior of the UHPC [15].

\subsubsection{Effect of fibers}

Goran et al. [16] conducted a study on circular UHPC-NSC composite columns subjected to concentric loading at Graz University of Technology. In this study different variables including the amount of steel fibers, the amount and arrangement of lateral reinforcement were considered. The experimental data show that the presence of fibers has no significant effect on the performance of composite columns. However, the presence of NSC shell outside the UHPC core leads to greater load-bearing capacity [16].

Another research conducted at the University of Kassel, Germany study the effect of the presence of steel fibers on the performance of Circular Steel Tube Confined Columns under axial loading. Two sets of columns of length $600 \mathrm{~mm}$ and $1000 \mathrm{~mm}$ with different amount of fiber content were tested. The experimental results show that the confinement effect enhances the performance of both UHPC and UHP-FRC regarding strength and ductility. The presence of the steel fibers does not increase the strength of the composite column, but it improves the ductile behavior of especially long columns [17]

A research team in Vietnam conducted an experimental study on axial strength of STCC columns containing UHPC and UHP-FRC at the University of Ton Duc Thang University. The steel fiber percentage of $1 \%$ and $2 \%$ were used. The experimental results show that the influence of fibers is insignificant on both strength and strain. Test results also revealed that 
the effect of confinement is more pronounced in columns which had no fibers. The steel fibers can prevent the local failure of the columns by providing additional strength [18].

The ductility and strength of the UHPC filled steel columns can be enhanced by adding at least $1 \%$ fibers by volume into the core material and by increasing the minimum contribution ratio of steel to $0.30[19]$.

The addition of steel fibers changes the mode of failure of UHPC columns from sudden explosive failure to ductile failure where not much chipping and spalling of the specimens was noted [20]. It was observed that the addition of fibers plays a significant role in the flexural strength of the UHPC. A $2.5 \%$ addition of steel fibers increased the flexural strength by 144 $\%$ in comparison to non-fiber UHPC beam [21].

\subsubsection{Structural Behavior of Confined UHPC Columns}

Soner et al. [22] conducted an experimental study of axial capacity and ductility of UHPC filled circular tubes. The test results are compared to different codes to compare their compatibility in designing composite columns. The test results showed that by increasing the steel tube thickness, the ductility of UHP-CFT is improved. However, it does not improve the axial strength of the columns the ACI and AS code predictions were too conservative while Eurocode 4 overestimated the bearing capacity [22].

William et al. [23] studied Axial Load Response of UHPC and High Strength Reinforcement. Eight UHPC columns were tested, and the results showed that the double hoop arrangement of transverse reinforcement without seismic crossties is most effective in enhancement of postpeak behavior. The results also show that the increase in the amount of transverse reinforcement increases the confinement effect and improves the toughness and ductility of the UHPC Columns [23].

Richard Liew and D.X Xiong [19] evaluates the performance of steel tubes filled ultra-high performance concrete by testing 27 specimens in the experiment. The study showed that filled 
tubes achieved ultra-high strength but became brittle near peak load. The test results showed that the Euro code could be safely applied to hollow steel tube filled with UHPC having strength of upto $200 \mathrm{MPa}$. The study included investigating 27 specimens including 18 steel tubes filled with UHPC, 4 with NSC and 5 hollow tubes to evaluate the performance. All the test results were compared with Eurocode 4 [19]. Figure 6 shows a comparison of test results with the Eurocode 4 predictions.

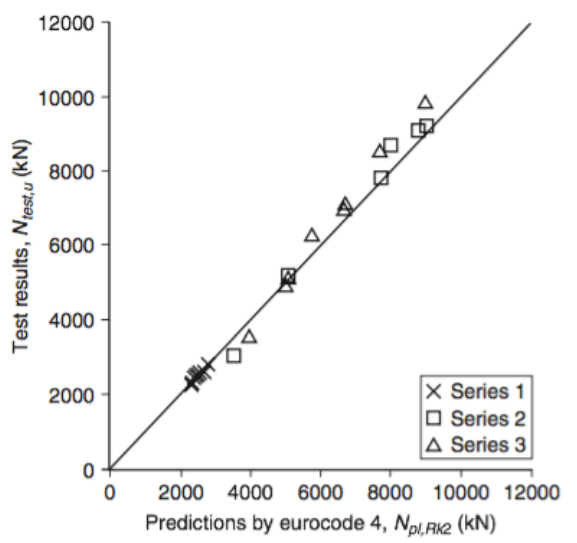

Figure 6. Eurocode 4 vs. Test Results [19]

The value of Poisson's ratio for UHPC is greater than NSC, and hence the confinement effect is greater in UHPC filled steel tubes than NSC filled steel tubes [19].

Liew et al. carried an investigation on the Concrete filled tubular columns and provided a design guide for such composite sections. The first phase of the study includes the testing of UHPC filled steel columns and the second phase provides the design method based on the Eurocode 4 approach. Figure 7 shows the test setup for a $4 \mathrm{~m}$ long column [1]. 

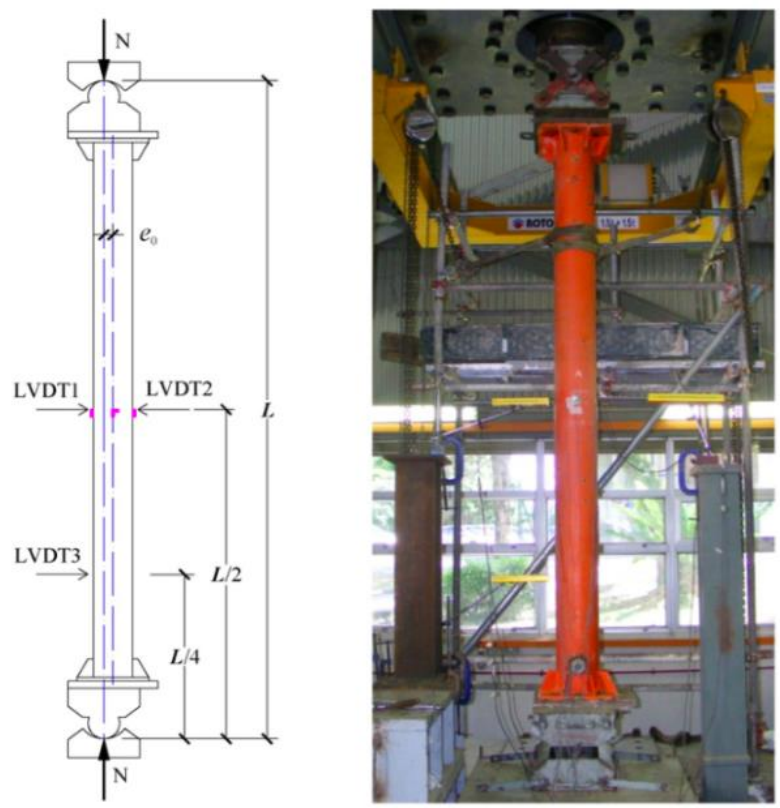

Figure 7. Schematic setup (left), Actual setup ( right) [1]

Figure 8 and Figure 9 shows the test results for concentric and eccentric loaded $4 \mathrm{~m}$ columns. The test results show that the Eurocode 4 predictions are conservative for the concentrically loaded columns. EC 4 suggests that the imperfection factor $\alpha_{m}$ can be used as 0.9 for S235 and S355 and 0.8 for S420 and S460 steel sections [1].

For the eccentrically loaded column, the imperfection factor $\alpha_{m}$ can be taken as 1.0 , showing that full plastic moment capacity can be used for eccentrically loaded columns. Hence for the composite sections it is desirable to have some eccentricity [1].

Test results and Eurocode 4 predictions for concentrically loaded specimens.

\begin{tabular}{llll}
\hline No. & $\mathrm{N}_{\text {test }}(\mathrm{kN})$ & $\mathrm{N}_{\mathrm{u}}(\mathrm{kN})$ & $\mathrm{N}_{\text {test }} / \mathrm{N}_{\mathrm{u}}$ \\
\hline CS-1 & 6324 & 5321 & 1.188 \\
$\mathrm{CS}-4$ & 8592 & 8403 & 1.022 \\
\hline
\end{tabular}

Figure 8. Table showing test results for concentric loaded column [1] 
Test results and Eurocode 4 predictions for eccentrically loaded specimens.

\begin{tabular}{|c|c|c|c|c|c|c|c|}
\hline \multirow[b]{2}{*}{ No. } & \multirow[b]{2}{*}{$\mathrm{N}_{\text {test }}(\mathrm{kN})$} & \multicolumn{2}{|c|}{$\alpha_{M}=0.8$} & \multicolumn{2}{|c|}{$\alpha_{M}=0.9$} & \multicolumn{2}{|c|}{$\alpha_{M}=1.0$} \\
\hline & & $\mathrm{N}_{\mathrm{u}}(\mathrm{kN})$ & $\mathrm{N}_{\text {test }} / \mathrm{N}_{\mathrm{u}}$ & $\mathrm{N}_{\mathrm{u}}(\mathrm{kN})$ & $\mathrm{N}_{\text {test }} / \mathrm{N}_{\mathrm{u}}$ & $\mathrm{N}_{\mathrm{u}}(\mathrm{kN})$ & $\mathrm{N}_{\text {test }} / \mathrm{N}_{\mathrm{u}}$ \\
\hline CS-2 & 4389 & 4070 & 1.078 & 4288 & 1.024 & 4484 & 0.979 \\
\hline CS-3 & 3246 & 2861 & 1.135 & 3063 & 1.060 & 3249 & 0.999 \\
\hline CS-5 & 5083 & 3767 & 1.349 & 4096 & 1.241 & 4395 & 1.156 \\
\hline CS-6 & 5284 & 4698 & 1.125 & 4999 & 1.057 & 5274 & 1.002 \\
\hline SS-1 & 5187 & 4612 & 1.125 & 4844 & 1.071 & 5051 & 1.027 \\
\hline SS-2 & 7136 & 5624 & 1.269 & 5828 & 1.225 & 6005 & 1.188 \\
\hline SS-3 & 4997 & 4247 & 1.177 & 4507 & 1.109 & 4742 & 1.054 \\
\hline \multicolumn{2}{|c|}{ Mean value } & & 1.180 & & 1.112 & & 1.058 \\
\hline \multicolumn{2}{|c|}{ Standard deviation } & & 0.096 & & 0.086 & & 0.082 \\
\hline
\end{tabular}

Figure 9. Table showing test result for eccentrically loaded column [1]

The second phase of the study provides the design guide for the composite section. It provides strain compatibility between steel and concrete. For the high strength filled steel tube columns, it is very important that steel yields before the concrete to develop the full plastic moment resistance capacity as the brittleness of high strength concrete increases at maximum stress. Hence it is very important to select compatible steel and concrete grade so that desired failure is achieved. Table 3 shows the compatibility table for different steel and concrete grades [1].

Table 3. Compatibility of steel and concrete grade [1]

\begin{tabular}{|c|c|c|c|c|c|c|c|}
\hline & S235 & S275 & S355 & S420 & S460 & S500 & S550 \\
\hline $\mathrm{C} 12 / 15$ & $\sqrt{ }$ & $\sqrt{ }$ & $\sqrt{ }$ & $x$ & $x$ & $x$ & $x$ \\
\hline $\mathrm{C} 16 / 20$ & $\sqrt{ }$ & $\sqrt{ }$ & $\sqrt{ }$ & $x$ & $x$ & $x$ & $x$ \\
\hline $\mathrm{C} 20 / 25$ & $\sqrt{ }$ & $\sqrt{ }$ & $\sqrt{ }$ & $x$ & $x$ & $x$ & $x$ \\
\hline $\mathrm{C} 25 / 30$ & $\sqrt{ }$ & $\sqrt{ }$ & $\sqrt{ }$ & $\sqrt{ }$ & $x$ & $x$ & $x$ \\
\hline C30/37 & $\sqrt{ }$ & $\sqrt{ }$ & $\sqrt{ }$ & $\sqrt{ }$ & $x$ & $x$ & $x$ \\
\hline C35/45 & $\sqrt{ }$ & $\sqrt{ }$ & $\sqrt{ }$ & $\sqrt{ }$ & $\sqrt{ }$ & $x$ & $x$ \\
\hline $\mathrm{C} 40 / 50$ & $\sqrt{ }$ & $\checkmark$ & $\sqrt{ }$ & $\sqrt{ }$ & $\sqrt{ }$ & $x$ & $x$ \\
\hline C45/55 & $\sqrt{ }$ & $\sqrt{ }$ & $\sqrt{ }$ & $\sqrt{ }$ & $\sqrt{ }$ & $\sqrt{ }$ & $x$ \\
\hline C50/60 & $\sqrt{ }$ & $\sqrt{ }$ & $\sqrt{ }$ & $\sqrt{ }$ & $\sqrt{ }$ & $\sqrt{ }$ & $x$ \\
\hline C55/67 & $\sqrt{ }$ & $\sqrt{ }$ & $\sqrt{ }$ & $\sqrt{ }$ & $\sqrt{ }$ & $\sqrt{ }$ & $x$ \\
\hline $\mathrm{C} 60 / 75$ & $\sqrt{ }$ & $\sqrt{ }$ & $\sqrt{ }$ & $\sqrt{ }$ & $\sqrt{ }$ & $\sqrt{ }$ & $x$ \\
\hline C70/85 & $\sqrt{ }$ & $\sqrt{ }$ & $\sqrt{ }$ & $\sqrt{ }$ & $\sqrt{ }$ & $\sqrt{ }$ & $\sqrt{ }$ \\
\hline C80/95 & $\sqrt{ }$ & $\sqrt{ }$ & $\sqrt{ }$ & $\sqrt{ }$ & $\sqrt{ }$ & $\sqrt{ }$ & $\sqrt{ }$ \\
\hline C90/105 & $\sqrt{ }$ & $\checkmark$ & $\sqrt{ }$ & $\sqrt{ }$ & $\sqrt{ }$ & $\checkmark$ & $\sqrt{ }$ \\
\hline C110/- & $\sqrt{ }$ & $\sqrt{ }$ & $\sqrt{ }$ & $\sqrt{ }$ & $\sqrt{ }$ & $\sqrt{ }$ & $\sqrt{ }$ \\
\hline C130/- & $\sqrt{ }$ & $\sqrt{ }$ & $\sqrt{ }$ & $\sqrt{ }$ & $\sqrt{ }$ & $\sqrt{ }$ & $\checkmark$ \\
\hline C150/- & $\sqrt{ }$ & $\sqrt{ }$ & $\sqrt{ }$ & $\sqrt{ }$ & $\sqrt{ }$ & $\sqrt{ }$ & $\sqrt{ }$ \\
\hline C170/- & $\sqrt{ }$ & $\sqrt{ }$ & $\sqrt{ }$ & $\sqrt{ }$ & $\sqrt{ }$ & $\sqrt{ }$ & $\sqrt{ }$ \\
\hline C190/- & $\sqrt{ }$ & $\sqrt{ }$ & $\sqrt{ }$ & $\sqrt{ }$ & $\sqrt{ }$ & $\sqrt{ }$ & $\sqrt{ }$ \\
\hline
\end{tabular}

Notes: " $\sqrt{ }$ " indicates compatible materials and " $\times$ " is not recommended.

Figure 10 to Figure 12 shows the Moment-Interaction curves for different grades of steel and concrete for specimen shown in Figure 13. 


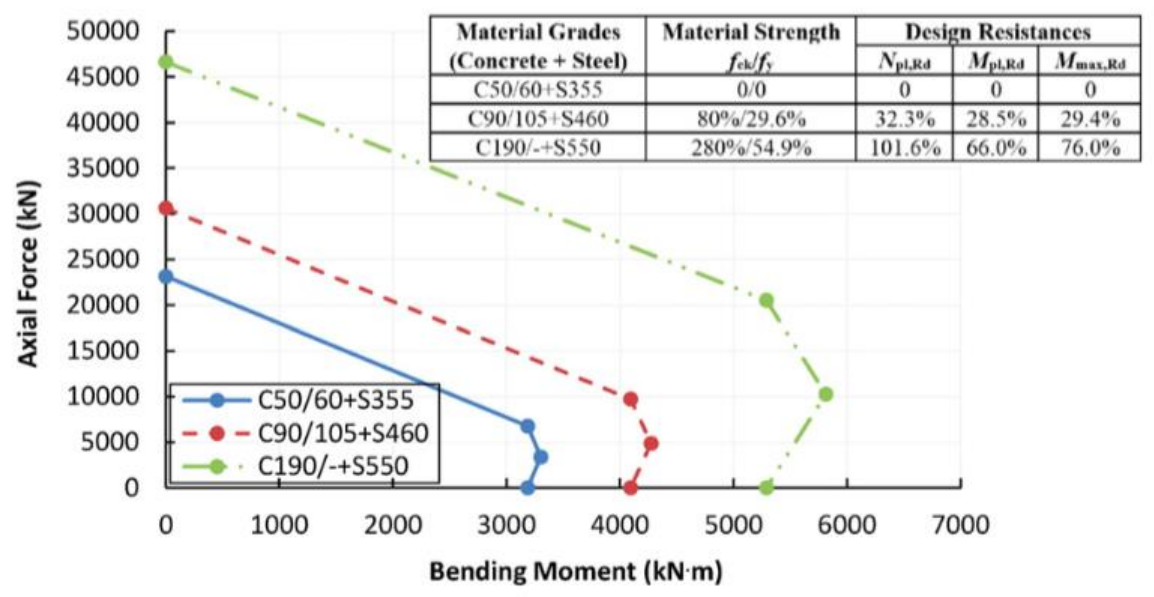

Figure 10. Effect of increasing both concrete and steel strengths [1]

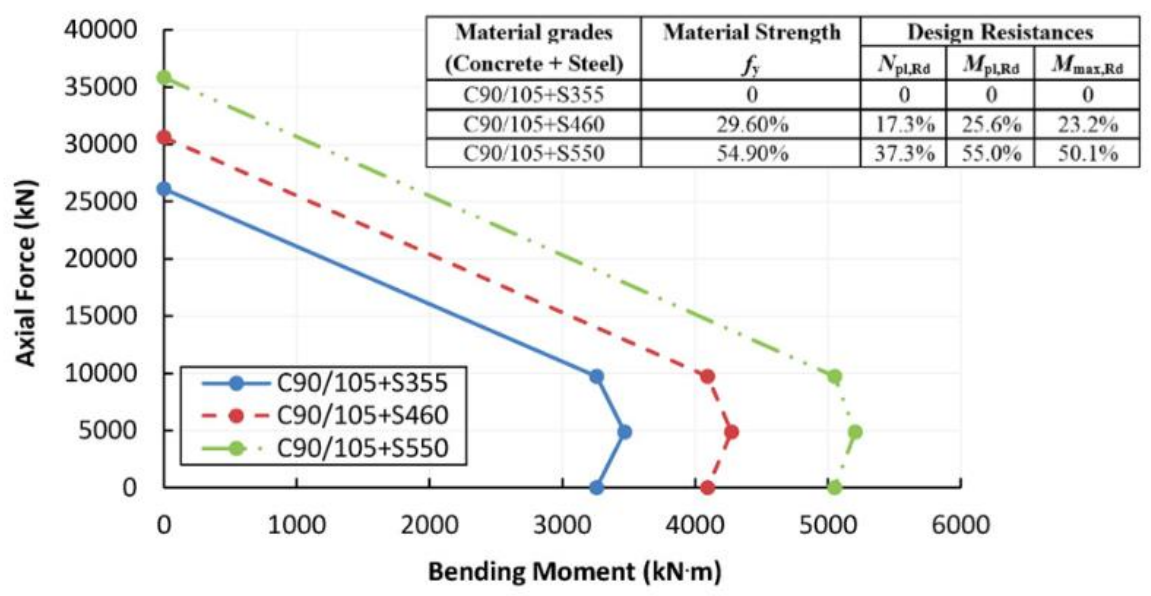

Figure 11. . Effect of increasing steel strength [1]

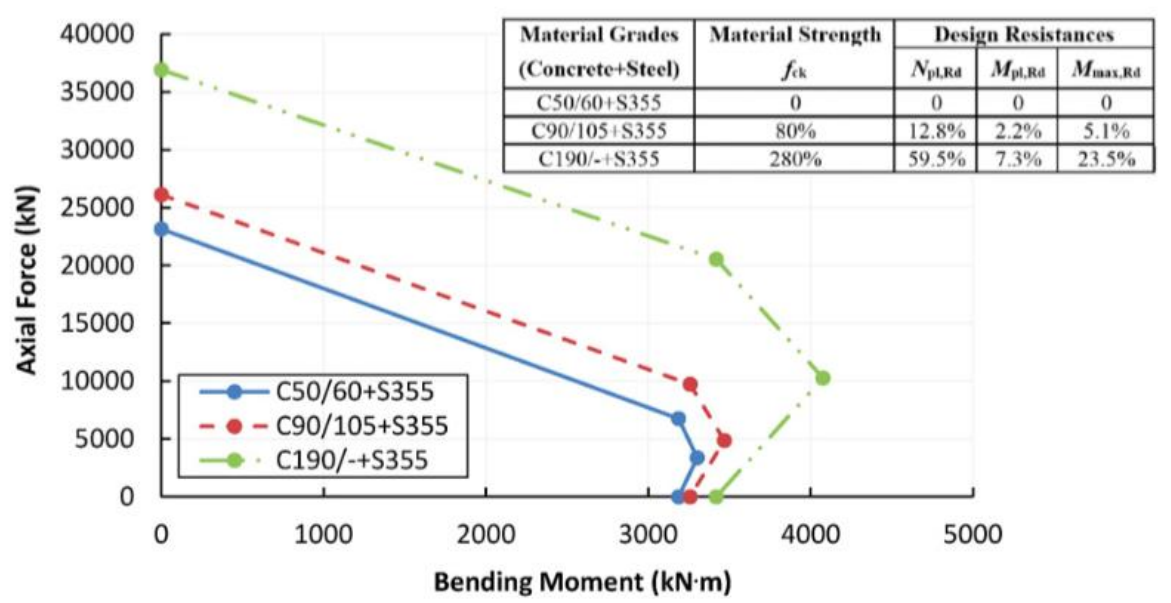

Figure 12. Effect of increasing concrete strength [1] 


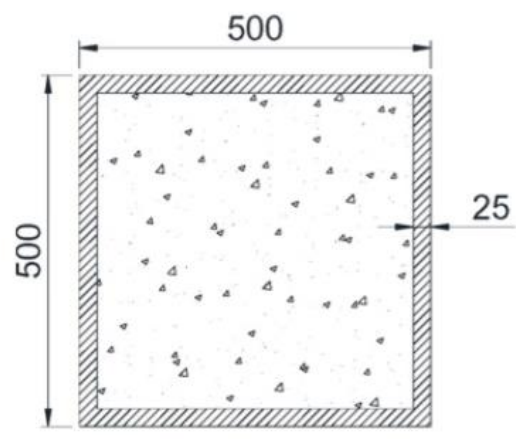

Figure 13. Specimen [1]

EC 4 can be safely extended for the design of composite sections with concrete strength of up to $190 \mathrm{MPa}$ and steel strength of $550 \mathrm{MPa}$. Class 4 steel sections cannot be used in this design guide. The concrete strength reduction factor of 0.8 should be used for concrete strength greater than $90 \mathrm{MPa}[1]$.

Youssef Hilal [24] an Meng student tested the performance of UHPC Filled Steel Tubes under the supervision of Dr. Hesham Marzouk and Dr. Hesham Othman at Ryerson University. 150 MPa UHPC mix was prepared using premixed materials produced by Lafarge and $90 \mathrm{MPa}$ HSC was prepared for comparison. Two sets of columns of length $600 \mathrm{~mm}$ and $1000 \mathrm{~mm}$ were tested under compression testing machine. Figure 14 shows the test setup for a confined column [24].

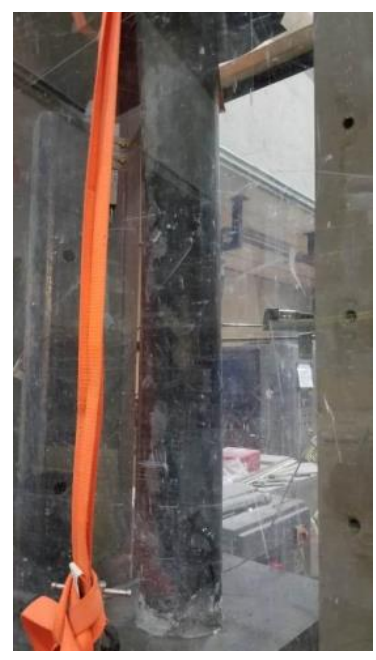

Figure 14. Test Setup [24] 
The test results show that UHPC performs much better than HSC. The confinement effect enhances the strength as well as ductility of columns. The experimental results were compared with different codes to evaluate their compatibility to design such composite columns. Figure 15 shows the Comparison of code predictions with experimental results. The results clearly show that Canadian code underestimates the capacity of Composite columns whereas Eurocode 4 approach gave close results to experiment [24].

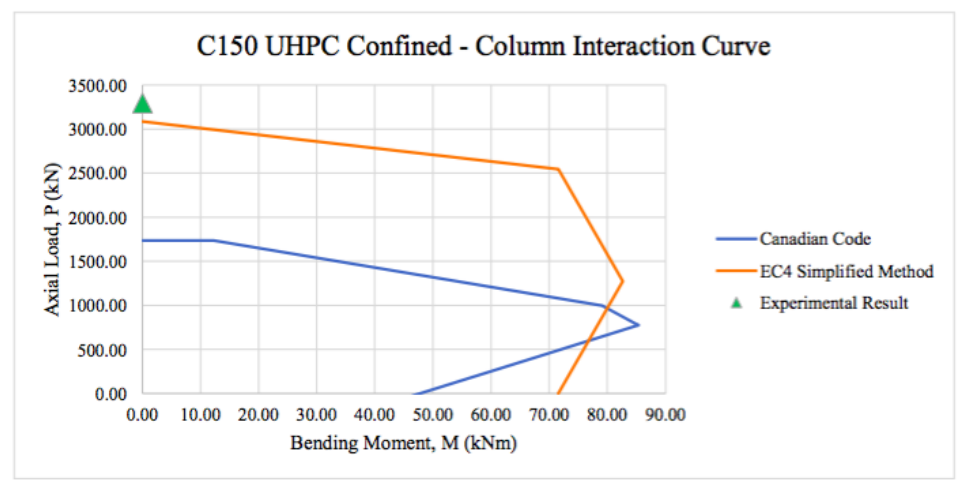

Figure 15. Column Interaction Diagram [24]

\subsubsection{Challenges for the use of UHPC}

Even though the use of UHPC has many advantages, it still faces many problems with its implementation especially in North America. Some of the key challenges are:

Due to the very low w/b ratio, normal mixers cannot be used for UHPC. High energy shear mixers are required.

$>$ The flexure behavior of UHPC depends mainly on the orientation of fibers, and hence it is very important to ensure effective distribution of fibers.

Rational design method for composite section has to be developed [25]. 


\section{Chapter 3}

\section{Experimental Investigation}

Chapter 3 discusses all the experiments performed in the structure lab. This chapter also describes the test specimens, mix proportions used, casting and testing machines used.

\subsection{Test Specimen}

In total 4 column specimens are tested under axial compression. In this study, the length of the specimen used was $2 \mathrm{~m}$ columns. The specimens were divided into different categories based on the type of concrete and confinement effect, two specimens made of UHPC with and without confinement effect and two specimens made of HSC with and without confinement effect. Table 4 shows the summary of specimens cast and tested in this study.

Table 4. Specimen summary

\begin{tabular}{|c|c|c|c|}
\hline Specimen & Material & Length $(\mathrm{mm})$ & Confinement $(\mathrm{Y} / \mathrm{N})$ \\
\hline UHPC $-\mathrm{CN}$ & UHPC & 2000 & $\mathrm{Y}$ \\
\hline UHPC - UN & UHPC & 2000 & $\mathrm{~N}$ \\
\hline HSC $-\mathrm{CN}$ & HSC & 2000 & $\mathrm{Y}$ \\
\hline HSC - UN & HSC & 2000 & $\mathrm{~N}$ \\
\hline
\end{tabular}

\subsubsection{Reinforcement details}

The longitudinal reinforcement consisted of $10 \mathrm{M}$ bars (CSA23-04), and the transverse reinforcement stirrups consisted of $6 \mathrm{~mm}$ bars bent in hexagonal shape. The stirrups were bent manually using the vice machine in the lab in the shape of a hexagon. Figure 16 shows the 6 $\mathrm{mm}$ bars as they came and the bent hexagonal shape. 


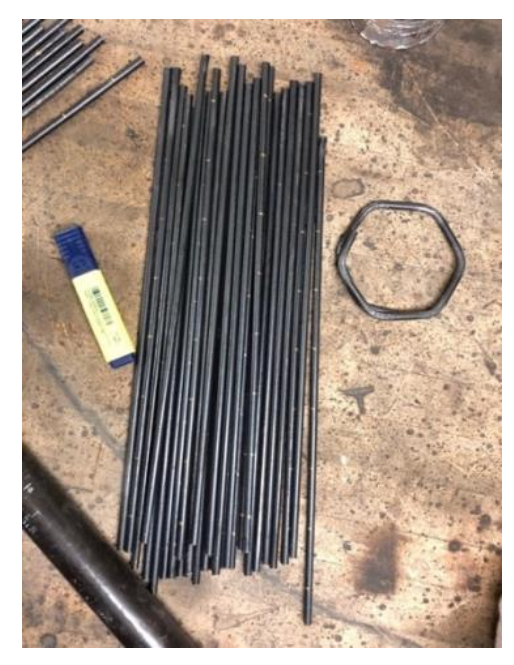

Figure 16. Transverse Reinforcement

Figure 17 shows the schematic method of bending the tie bars. The total length of the tie bars was $300 \mathrm{~mm}$ which was divided into 6 segments of $50 \mathrm{~mm}$ each. Then each segment was bent to an angle of $120^{\circ}$ to obtain a hexagon.

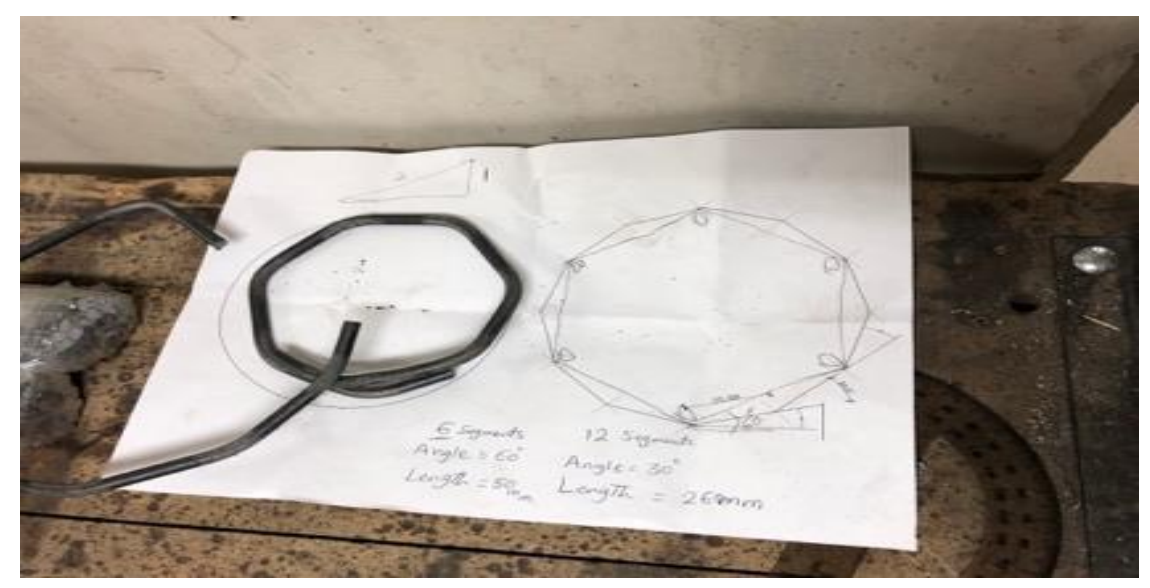

Figure 17. Schematic method of bending Tie bars

The next step after making the ties was to make the reinforcement cage. The spacing of the tie bars was $100 \mathrm{~mm}$ for all the specimens. To attach the tie bars to longitudinal bars, zip ties were used as shown in Figure 18. 


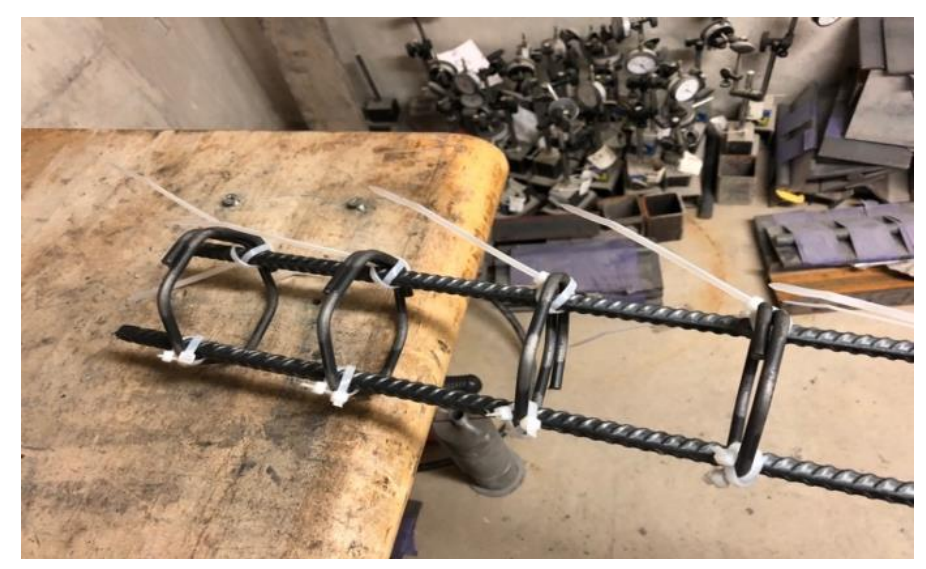

Figure 18. Binding tie bars and longitudinal bars using zip ties

After trying all the tie bars at a spacing of $100 \mathrm{~mm}$ the final cage for the columns was obtained as shown in Figure 19.

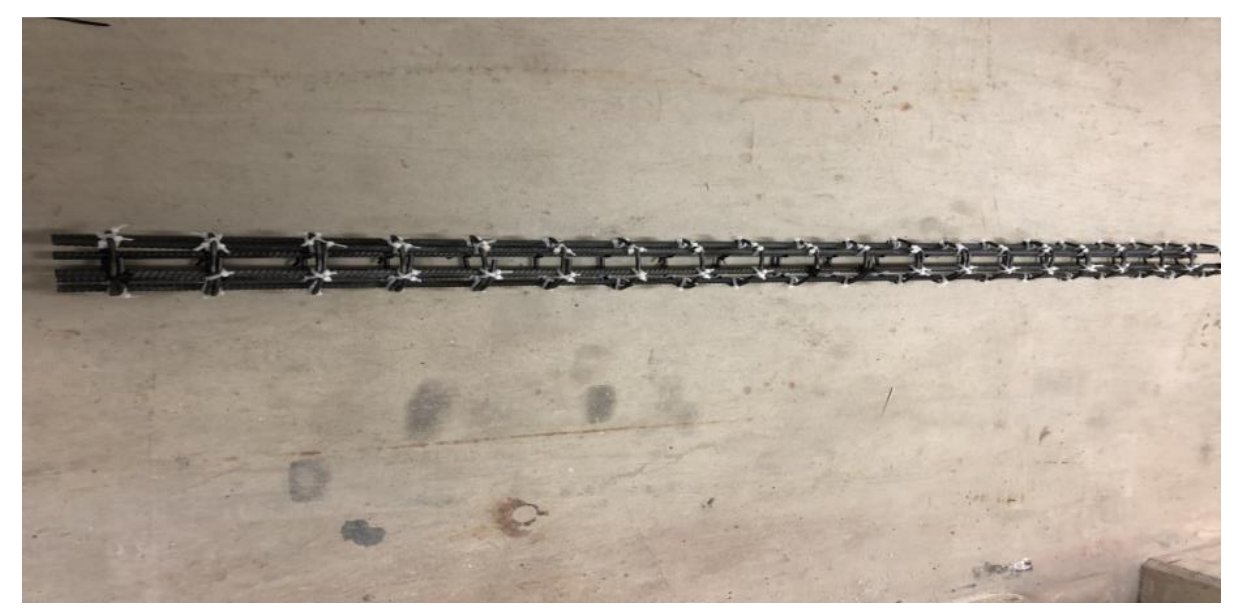

Figure 19. Two meters reinforcement cage

\subsubsection{Formwork}

Making the formwork for the specimens was a simple job. For the confined specimens the steel tube used for the confinement effect acted as formwork. For the unconfined specimen, Sonotubes which is a large cardboard tube that serves as a formwork and hold the wet concrete in place. Sonotubes of 6-inch diameter and $2 \mathrm{~m}$ length were used. After casting these tubes 
were cut before testing the specimens to ensure that no confinement effect was provided to unconfined specimens.

\subsubsection{Casting and Curing}

The scope of this study required two types of mixes, High strength concrete mix, and UHPC mix. The target strength for HSC was $90 \mathrm{MPa}$, and UHPC was $150 \mathrm{MPa}$. These mixes cannot be mixed using a normal mixer, and hence shear mixer of capacity $250 \mathrm{~L}$ was used to mix. UHPC mix was prepared and cast first and HSC later. Table 5 shows the mix proportions used for HSC and UHPC. UHPC used was obtained from Ductal® North America [14].

Table 5. Mix Proportions for HSC and UHPC

\begin{tabular}{|c|c|c|}
\hline Ingredients & UHPC & HSC \\
\hline Design strength (MPa) & 150.0 & 90.0 \\
\hline Volume (L) & 100.0 & N/A \\
\hline Premix bags (Kg) & 255.0 & 105.0 \\
\hline Sand (Kg) & N/A & 165 \\
\hline Pea Gravel (Kg) & N/A & 80.0 \\
\hline Cement (Kg) & N/A & N/A \\
\hline Fibers (Kg) & 16.0 & 23.0 \\
\hline Water (Kg) & 13.5 & 1.0 \\
\hline Superplasticizer (Kg) & 3.1 & 8.0 \\
\hline Silica -Fumes (Kg) & N/A & 0.29 \\
\hline W/C & - & \\
\hline & & \\
\hline
\end{tabular}


UHPC - MIX was prepared by first adding the premix bags into the shear mixer and then about $1 / 4^{\text {th }}$ of the fibers and then were dry mixed for $30-40$ seconds. Half the quantity of water and superplasticizer was mixed and poured into the mixer. The remaining water and superplasticizer were added slowly and mixed until a flowable and consistent mix was obtained.

HSC - MIX was prepared by first dry mixing of the cement, sand, and aggregates and then adding water and superplasticizer in proportions.

Not much difficulty was faced during the casting of UHPC due to the very good followability and was easily poured into the specimens. Casting HSC was difficult due to presence of coarse aggregates, to make sure no voids are created, a lot of tamping was done while casting HSC into tubes. All the specimens were cured for 7 days by watering the top face. In spite of proper care, voids were formed in the specimens. These voids were later filled by using UHPC mix. All the specimens were allowed to harden for 28 days before testing.

\subsection{Experimental Setup and Testing}

The experimental setup consisted of axial loading the specimens in a hydraulic compressive machine and recording the mid-height displacement. All the specimens were tested using a Compressive hydraulic machine that was recently bought by Ryerson University. This machine has a capacity of $1000 \mathrm{KN}$ and can test $2 \mathrm{~m}$ long columns. Figure 20 shows the Compressive testing machine used. 


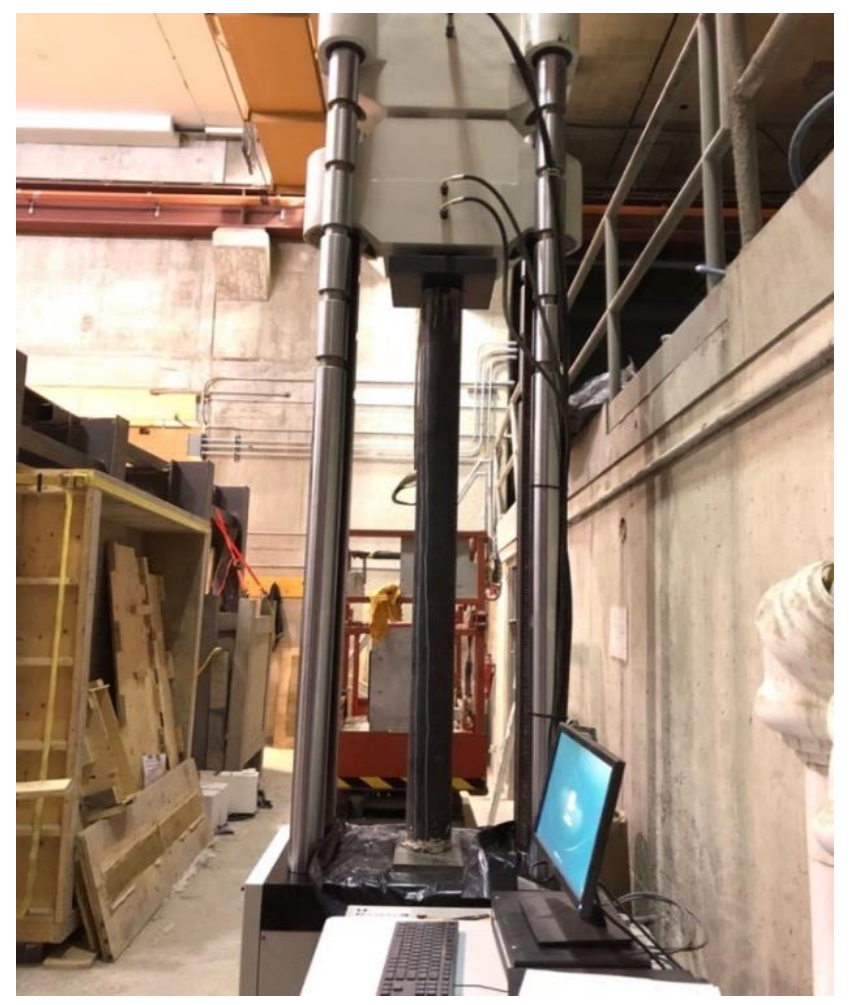

Figure 20. Compressive Testing Machine

To measure the deformations under the axial loading, two transducers were used which were placed at an angle of $90^{\circ}$ to each other at the mid-height of the specimens. Figure 21 shows the transducers used in the experiment and Figure 22 shows the setting of Transducers at an angle of $90^{\circ}$ to each other to measure axial deformations in all the directions.

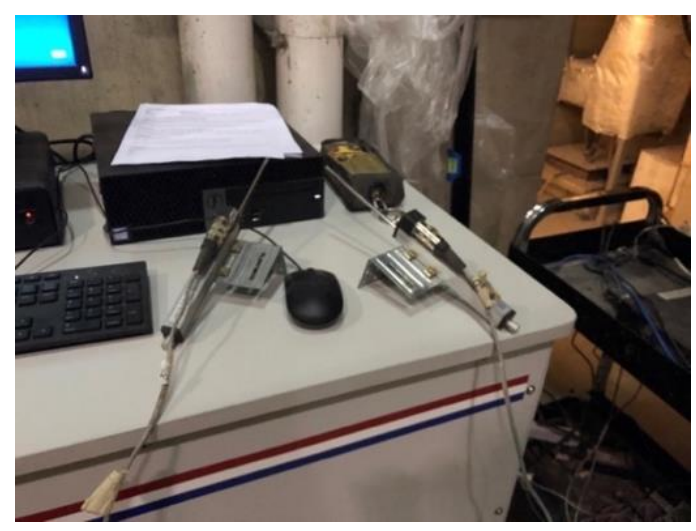

Figure 21. Transducer 


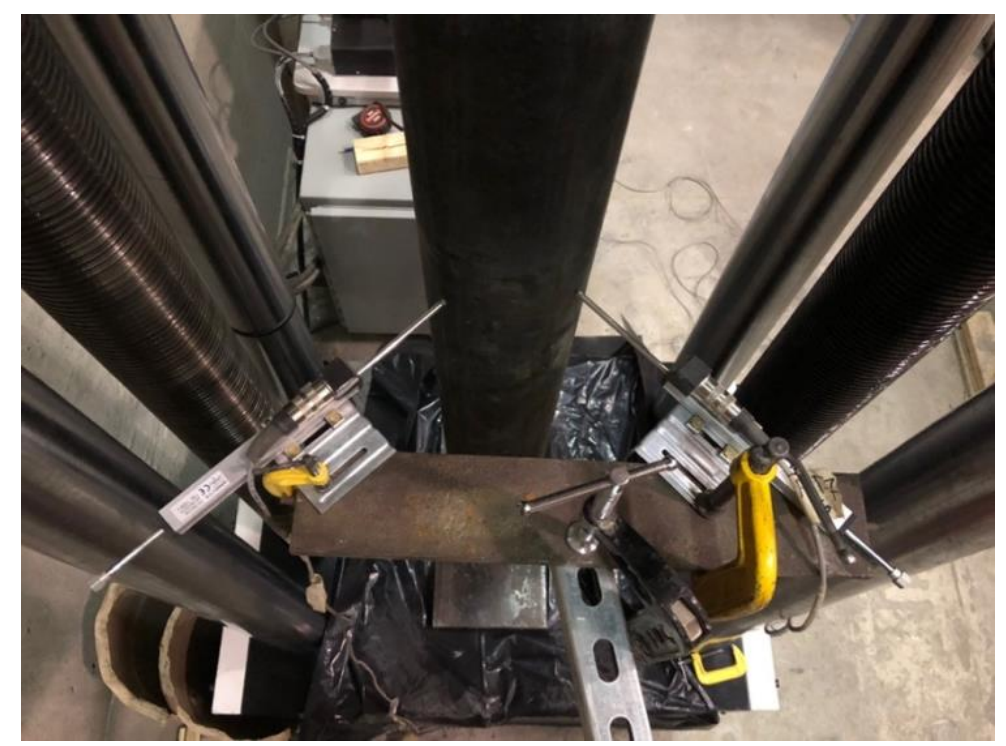

Figure 22. Transducer setup

After setting up the transducers, the load was applied at a rate of $0.36 \mathrm{~mm} / \mathrm{min}$ until $40-50 \%$ of the peak load was reached, and readings were noted at the rate of 1reading/second.

\subsection{Test Results}

All the 4 specimens were tested in compressive machine one by one.

Table 6 shows the test results obtained. For the confined specimen the capacity was much greater than the capacity of the machine. For the unconfined specimens, UHPC reached a maximum value of $742 \mathrm{KN}$ and $\mathrm{HSC}$ which was a reference specimen reached only $337 \mathrm{KN}$. The results clearly show the performance of UHPC is much better than HSC. Although results could not be obtained for confined specimens, it is seen that the capacity of confined specimens is much greater than unconfined specimens implying the benefit of the confinement effect. The deflection values give a better idea about the advantage of the confinement effect. On comparing the values, it can be seen that the deflection of confined specimens was way less than unconfined. These values signify that the presence of a steel tube prevents the outward buckling of the concrete and thus increases the ductility.

Table 6. Test results 


\begin{tabular}{|c|c|c|c|c|}
\hline $\begin{array}{c}\text { Maximum Load } \\
(\mathrm{KN})\end{array}$ & $\begin{array}{c}\text { UHPC }-\mathrm{C} \\
\text { Beyond machine } \\
\text { capacity }\end{array}$ & UHPC - UN & HSC - C & HSC - UN \\
\hline $\begin{array}{c}\text { Maximum } \\
\text { Deflection } \\
(\mathrm{mm})\end{array}$ & $\begin{array}{c}6 \text { at machine } \\
\text { capacity }\end{array}$ & 10.05 & $\begin{array}{c}\text { Beyond machine } \\
\text { capacity }\end{array}$ & $337(\mathrm{KN})$ \\
\hline
\end{tabular}

Figure 23 shows the load vs. axial deformation of Unconfined HPC and UHPC specimens. On comparing the curves, it is seen that the peak load capacity of UHPC is very high as compared to the peak load capacity of the HSC. However, when the post load part of the curve is compared, it shows that UHPC shows a sudden drop in load and failure is in-elastic whereas HSC shows a very elastic behavior. After the peak load is achieved, the drop in load is very slow, and it is also seen that after a certain drop of load it again started carrying more load before finally failing. These results very well comply with all the research work done in the field of HSC and UHPC stating that UHPC shows very brittle behavior which was also seen in this experiment. Thus,

these results show that the problem with UHPC would be its low ductility. This problem of ductility can be solved by encasing the UHPC core with steel tube.

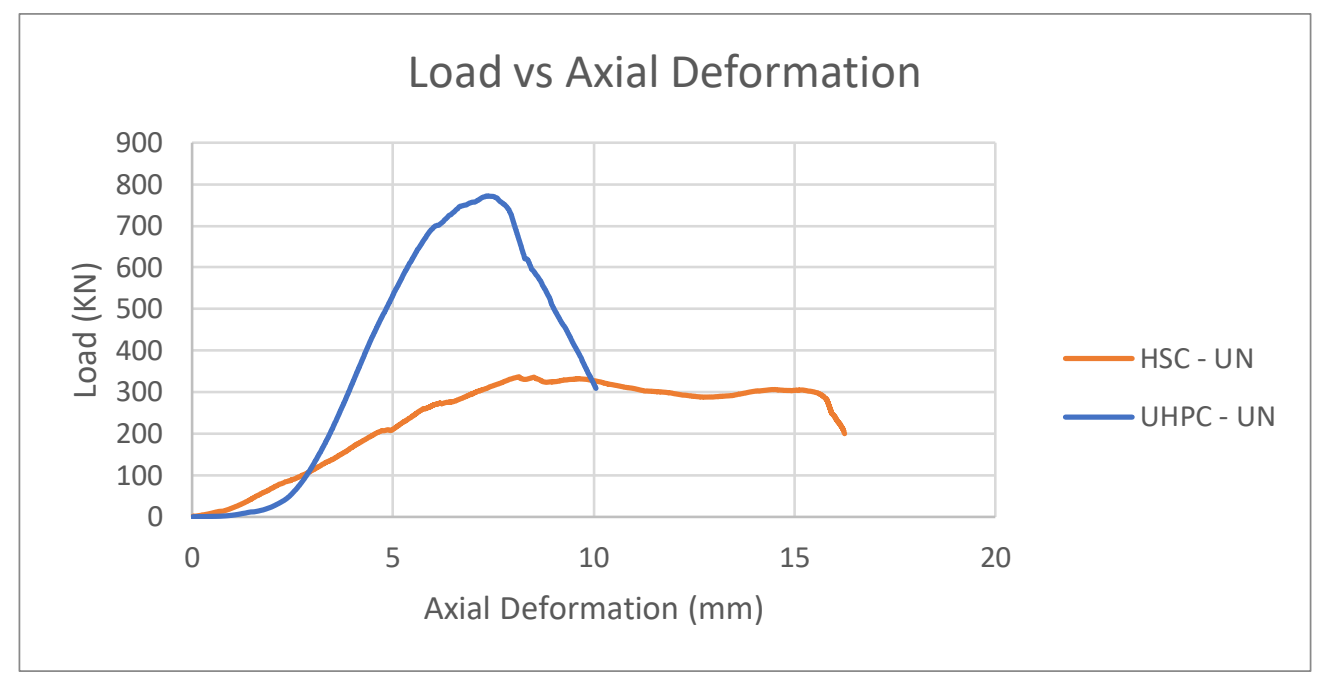

Figure 23. load vs. axial deformation of Unconfined HPC and UHPC specimens 


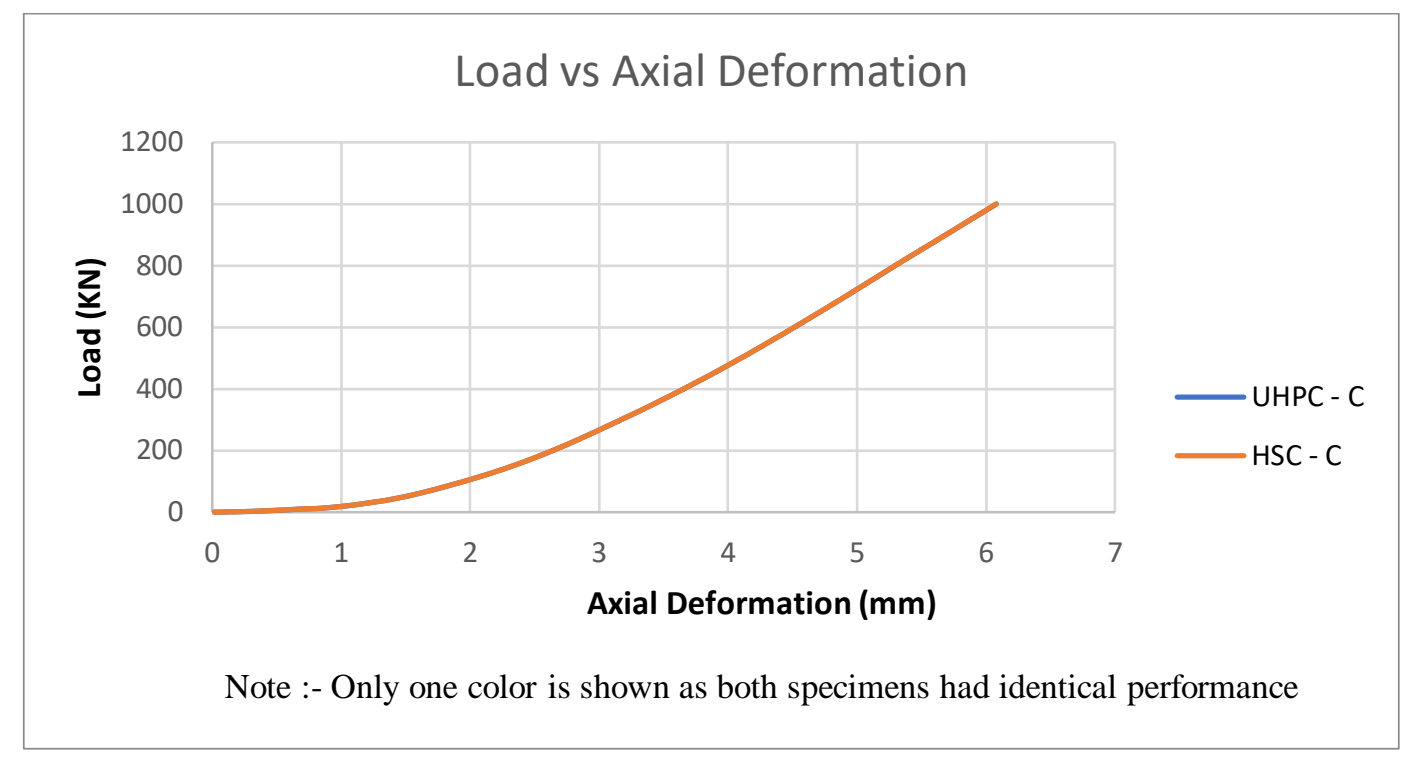

Figure 24. load vs. axial deformation of confined HPC and UHPC specimens

Figure 24 shows the load vs. axial deformation of UHPC and HSC confined specimens. It is seen that no failure was developed up to $1000 \mathrm{KN}$ which was the capacity of the machine. One interesting thing can be seen the curves for both HSC and UHPC confined sections are same. From this one idea can be clearly made that the confinement of the steel tube increases the load capacity and buckling of the concrete.

\subsection{Failure Modes}

Since the confined specimens had a capacity greater than the loading machine no failure mode could not be seen in those two specimens. Figure 25 Shows the deformed shapes for unconfined sections. For both of the specimens, the failure was mainly due crushing of the top part of the specimens. During the testing of the UHPC-UN specimen, some cracking sound was heard, and it showed chipping up to a greater length than compared to HSC. These results imply the brittleness of the UHPC. 


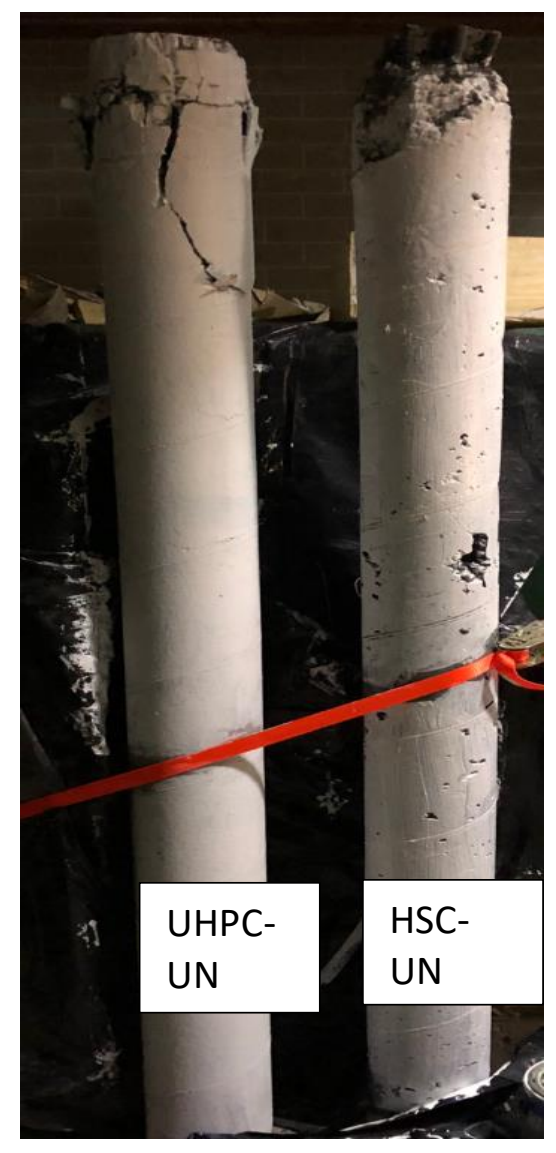

Figure 25. Failure modes of Unconfined UHPC and HSC. 


\section{Chapter 4}

\section{Analytical approach of Composite Steel/UHPC section}

An analytical method was used to predict the composite steel column filled with UHPC their strength. The column Interaction diagram was developed using Eurocode 4 by considering the buckling effect and the bending effects.

\subsection{Eurocode analysis}

The results for confined sections could not be obtained due to the capacity of the machine being lower than the capacity of the confined sections. A computer analysis programme was done to assess the performance of confined section with some hypothetical Super-frame with some rough assumptions. To have accurate results, the confined sections were analyzed by developing Column Interaction diagrams using Eurocode 4 simplified approach. The fourpoint A, B, C, and D were calculated. Figure 26 shows the Column - Interaction diagram.

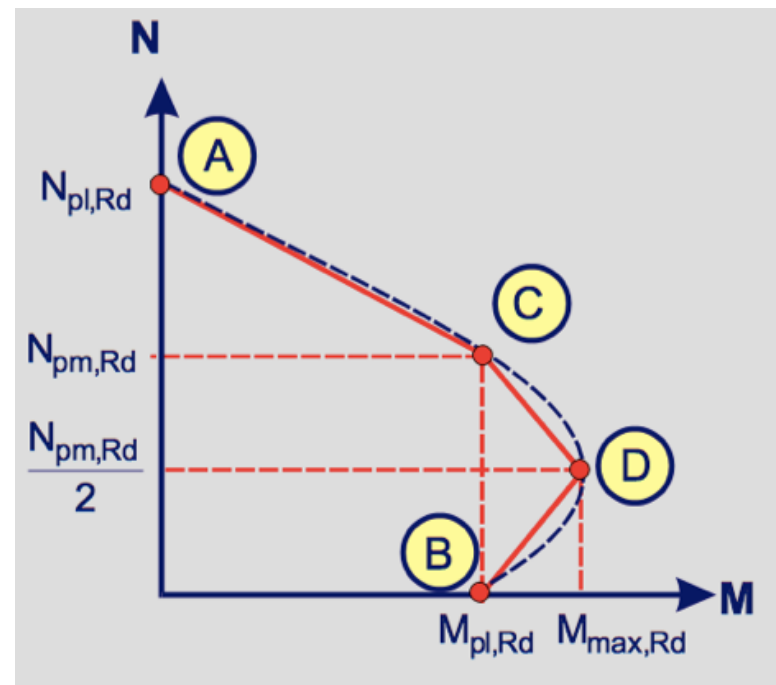

Figure 26. Interaction Diagram [EC 4]

$>$ Point A refers to the point of pure axial compression.

Point $\mathrm{B}$ refers to the point of pure bending and no axial force. 
$>$ Point $\mathrm{C}$ refers to the point when the cross-section is under partial compression, and axial force is resultant from compressive stresses.

Point $\mathrm{D}$ corresponds to maximum plastic moment resistance.

\subsubsection{Design Parameters}

Concrete $\left(f_{c k}\right)$

Steel tube $\left(f_{y}\right)$

Reinforcement $\left(f_{\mathrm{y}}\right)$

Column length

Inner Diameter of Tube (d)

Thickness of Tube ( $\mathrm{t}$ )

Outer Diameter of Tube (D)
$150 \mathrm{MPa}$

$400 \mathrm{MPa}$

$400 \mathrm{MPa}$

$2000 \mathrm{~mm}$

$127 \mathrm{~mm}$

$6.55 \mathrm{~mm}$

$127+2 * 6.55)=140.1 \mathrm{~mm}$

\subsubsection{Column - Interaction Diagram Procedure}

The procedure to develop Interaction diagram was followed according to the design guide by Lieu and Xiong [26]. For UHPC having a strength greater than $90 \mathrm{MPa}$, design guide [26] recommends a reduction factor of 0.8 . The equation 4.1 gives the strength reduction factors.

$$
\eta=\left\{\begin{array}{cr}
1.0-\left(f_{c k}-50\right) / 200 & 50 M P a<f_{c k}<90 M P a \\
0.8 & f_{c k}>90 M P a
\end{array}\right.
$$

The modulus of elasticity of concrete is also modified according to the strength reduction factor. The equation 4.2 gives the modified elasticity modulus [26].

$$
\begin{gathered}
E_{c m}=22\left[\left(\eta \cdot f_{c k}+8\right) / 10\right]^{\wedge} 0.3 \\
E_{c m}=47 \mathrm{GPa}
\end{gathered}
$$

\subsubsection{Point A, Pure axial load $\left(0, \mathrm{~N}_{\mathrm{pl}, \mathrm{Rd}}\right)$}


The following equation (4.3) was used to compute the axial capacity of the column which takes into account the effect of confinement [26].

$$
N_{p l, R d}=\eta_{a} A_{a} f_{y d}+A_{c} f_{c d}\left(1+\eta_{c} \frac{t_{t u b e} f_{y}}{d f_{c d}}\right)+A_{s} f_{s d}
$$

The value of all the unknowns is calculated and substituted in equation 4.3 to get the Axial capacity of $\left(\mathrm{N}_{\mathrm{pl}, \mathrm{Rd}}=3569.79 \mathrm{KN}\right)$. The values of $\eta_{a}$ and $\eta_{c}$ are taken as 0.25 and 4.9 as given by Eurocode 4 for stocky centrally loaded columns [26].

Since the Column was a long column, the buckling reduction factor $(\chi)$ was calculated. The equation 4.4 gives the buckling capacity of the column[26].

$$
\begin{gathered}
N_{b, R d}=\chi N_{p l, R d} \\
\chi=\frac{1}{\Phi+\sqrt{\Phi^{2}-\lambda^{2}}} \\
\Phi=0.5[1+\alpha(\lambda-0.2)+\lambda]
\end{gathered}
$$

In the equation, $4.6 " \alpha$ " is the imperfection factor whose value depends upon the buckling curve for the section. Eurocode 4 defines the buckling curves for composite sections based on ratio of reinforcement [26].

Buckling curve is 'a' for $\rho_{s}<3 \%$ and 'b' for $3 \%<\rho_{s}<6 \%$. The $\rho_{s}$ for the specimen is 4 $\%$ and hence the buckling curve is ' $b$ '. 
Table 7 shows the imperfection factor.

Table 7. Imperfection factor [26]

\begin{tabular}{|l|l|l|l|l|l|}
\hline Buckling curve & $a_{o}$ & a & b & c & d \\
\hline Imperfection factor & 0.13 & 0.21 & 0.34 & 0.49 & 0.76 \\
\hline
\end{tabular}

$$
\alpha=0.34
$$

The only factor left to calculate the buckling reduction factor is " $\lambda$ ". The following set of equations will provide " $\lambda$ ".

$$
\begin{gathered}
\lambda=\sqrt{\frac{N_{p l, R K}}{N_{c r}}} \\
N_{c r}=\frac{\pi^{2}(E I)_{e f f}}{L^{2} \text { eff }} \\
N_{p l, R k}=A_{a} f_{y}+A_{c} f_{c k}+A_{s} f_{y} \\
(E I)_{e f f}=E_{a} I_{a}+E_{s} I_{s}+0.6\left(E_{c m} I_{c}\right)
\end{gathered}
$$


The effective length for buckling is assumed to be $0.7 \mathrm{~L}$ for specimens effectively restrained at both the ends [26]. This assumption is well justified as both the ends of the specimens were restrained in the experiment.

$$
L_{e f f}=0.7 \mathrm{~L}
$$

By solving all the equations from (4.6) to (4.12), the buckling resistance factor $(\chi)$ is obtained as 0.84 and by substituting its value in equation (4.4), the buckling resistance capacity of the column works out to be $2998.62 \mathrm{KN}$.

Point $(\mathrm{A})=2998.62 \mathrm{KN}$.

\subsubsection{Point B, Pure Bending $\left(\mathrm{M}_{\mathrm{pl}, \mathrm{Rd},}\right.$ ) $)$}

At this stage, the section is purely under bending, and no axial force is formed. The very first step to calculate Point B is to find the depth of the neutral axis ( $\left.i_{n}\right)$. The depth of the neutral axis is given by equation 4.13 [26].

$$
h_{n}=\frac{A_{c} f_{c d}}{2 D f_{c d}+4 t_{t u b e}\left(2 f_{y d}-f_{c d}\right)+4 t_{s}\left(2 f_{s d}-f_{c d}\right)}
$$

The second step to find the Point B is to compute the plastic section modulus of steel tube, concrete, and reinforcement. To make it simple, the reinforcement is converted into an equivalent tube using the following 2 equations [26].

$$
\begin{gathered}
t_{s}=\frac{A}{\pi(d-2 * \text { cover })} \\
D_{s}=d-(2 * \text { cover })+t_{s}
\end{gathered}
$$




$$
\begin{gathered}
W_{p c}=\frac{(d-2 * t)^{3}}{6} \\
W_{p c, n}=\left(d-2 t_{\text {tube }}\right) * h_{n}{ }^{2} \\
W_{p a}=\frac{d^{3}}{6}-W_{p c} \\
W_{p a, n}=d h^{2}{ }_{n}-W_{p c, n} \\
W_{p s}=\frac{D_{s}{ }^{3}-\left(D_{s}-2 t_{s}\right)^{3}}{6} \\
W_{p s, n}=2 t_{s} h_{n}^{2}
\end{gathered}
$$

After computing all the values from equation 4.13 to 4.21 , they are substituted in the final

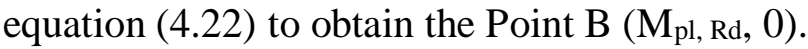

$$
\begin{aligned}
& M_{p l, R d}=\left(W_{p a}-W_{p a, n}\right) f_{y d}+\left(W_{p s}-W_{p s, n}\right) f_{s d}+0.5 *\left(W_{p c}-W_{p c, n}\right) f_{c d} \\
& M_{p l, R d}=66.05 \mathrm{kNm}
\end{aligned}
$$

\subsubsection{Point C, Prior to yielding of steel}

The design guide [26] gives the following equation (4.23) to calculate the Point C.

$$
N_{p m, R d}=A_{c} f_{c d}\left(1+\eta_{c} \frac{t f_{y}}{d f_{c d}}\right)
$$

By substituting all the values, the value of $\mathrm{N}_{\mathrm{pl}}$, Rd is obtained as $3059.40 \mathrm{KN}$. The corresponding value of the moment is the same as calculated for point $\mathrm{B}$ of $\mathrm{M}_{\mathrm{pl}, \mathrm{Rd}}=66.05 \mathrm{KNm}$.

\subsubsection{Point D, Balanced Point}


For calculating the moment capacity at the balance point is given by the equation (4.24) provided by the design guide [26]. The corresponding value of axial capacity is computed by taking half the value of axial capacity at Point C [26].

$$
\begin{gathered}
N_{D R}=1499.31 K N \\
M_{p l, R d}=W_{p a} * f_{y d}+W_{p s} * f_{s d}+0.5 * W_{p c} * f_{c d} \\
\mathrm{M}_{\mathrm{pl}, \mathrm{Rd}}=80.49 \mathrm{KNm}
\end{gathered}
$$

Table 8 shows all the computed point A, B, C, and D.

Table 8. Column Interaction Point for UHPC.

\begin{tabular}{|l|c|c|}
\hline Interaction Point & $\mathrm{N}_{\mathrm{pl}, \mathrm{Rd}}(\mathrm{KN})$ & $\mathrm{M}_{\mathrm{pl}, \mathrm{Rd}}(\mathrm{KNm})$ \\
\hline A - Pure Axial capacity & $2998.62 \mathrm{KN}$ & 0.00 \\
\hline B - Pure Bending capacity & 0.00 & 66.05 \\
\hline C - Prior to Steel yielding & 3059.40 & 66.05 \\
\hline D - Balanced Point & 1499.31 & 80.49 \\
\hline
\end{tabular}

Following the same procedure, the Column - Interaction was developed for HPC for Strength of $90 \mathrm{MPa}$. Table 9 shows the points for HPC.

Table 9.Column - Interaction points for HPC

\begin{tabular}{|l|c|c|}
\hline Interaction Point & $\mathrm{N}_{\mathrm{pl}, \mathrm{Rd}}(\mathrm{KN})$ & $\mathrm{M}_{\mathrm{pl}, \mathrm{Rd}}(\mathrm{KNm})$ \\
\hline A - Pure Axial capacity & $2476.48 \mathrm{KN}$ & 0.00 \\
\hline $\mathrm{B}-$ Pure Bending capacity & 0.00 & 66.71 \\
\hline C - Prior to Steel yielding & 2299.72 & 66.71 \\
\hline D - Balanced Point & 1238.24 & 70.25 \\
\hline
\end{tabular}

Figure 27 shows the column Interaction diagram for HPC and UHPC confined specimens. The performance of the UHPC - Confined Column is better than the HPC Confined Column as depicted by the Curves. 


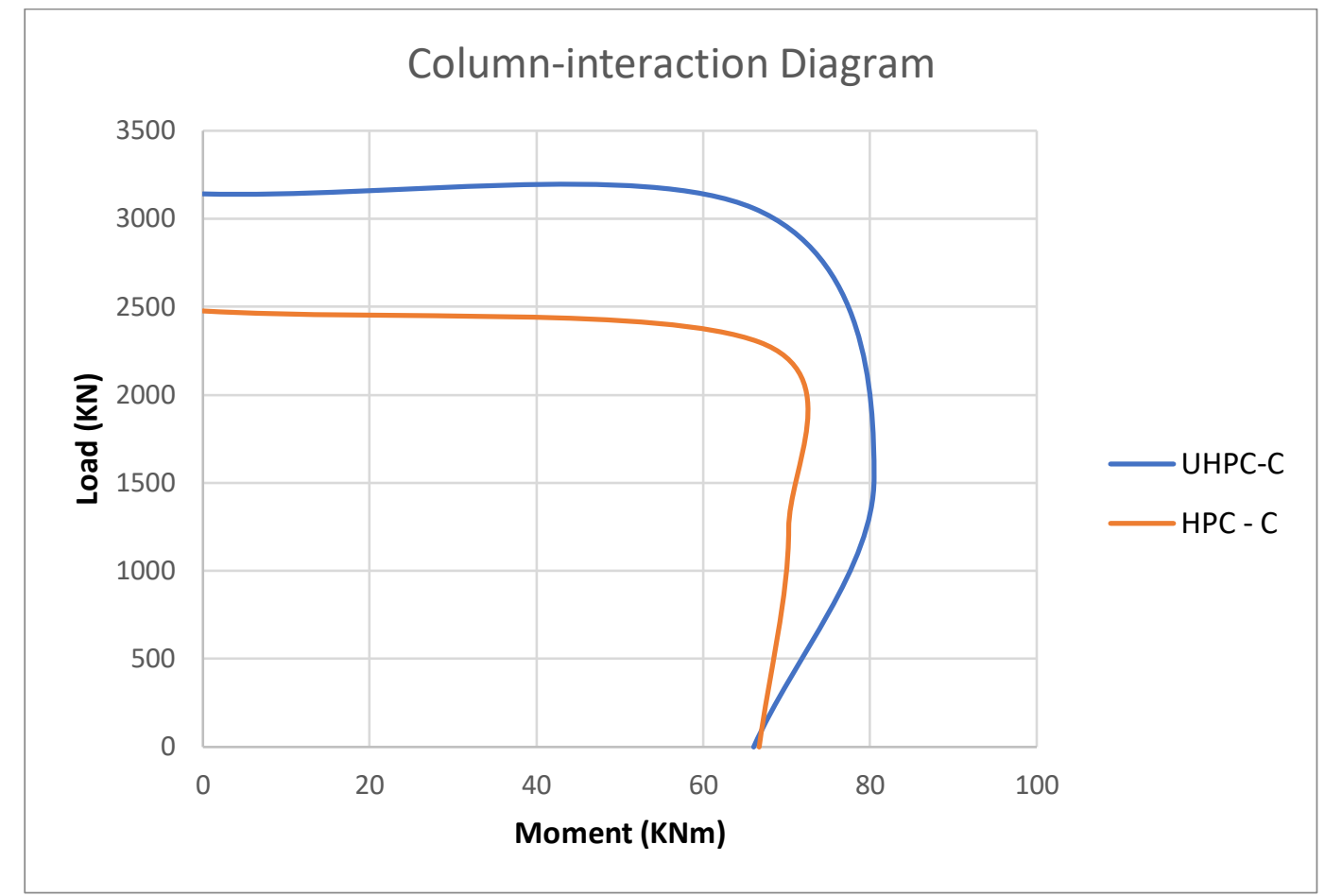

Figure 27. Column - Interaction Diagram for confined UHPC and HPC

The detailed calculations are shown in Appendix - A.

\subsection{Discussion}

For high rise building, the composite sections are subjected to effects of both large compressive force and bending moment. Thus, the composite sections must have high compressive and bending resistance. The interaction diagram shows that the increase in concrete strength improves the effectiveness of composite sections in resisting both compressive and bending effects. Thus the composite sections are the most viable option for the high rise construction. 


\section{Chapter 5}

\section{Numerical Analysis}

In this chapter, a numerical study was conducted to evaluate the effectiveness of the composite steel frame filled with UHPC Commercially known as the supper frame compared to the use of braced steel for the high rise construction. The model was developed using ETABS v17.0.0. The Canadian design code was used for the model section revisions. Following four types of systems were modeled and studied under the effect of the lateral displacement.

1. Steel Column

2. UHPC Columns

3. Hollow Steel Tube filled with UHPC known as Super-frame

4. Steel braced frame

\subsection{Case Study 1- Super-Frame Model}

The study [1] shows a super-frame model. The model consists of a mega-column extending to 6-7 floors. The outrigger truss system is provided at 6-7 floors that transfer the accumulated load to the columns. Figure 28 shows super-frame model. A super-frame model was made using E-tabs in lieu of this study to see the performance of the Composite UHPC filled steel tubes.

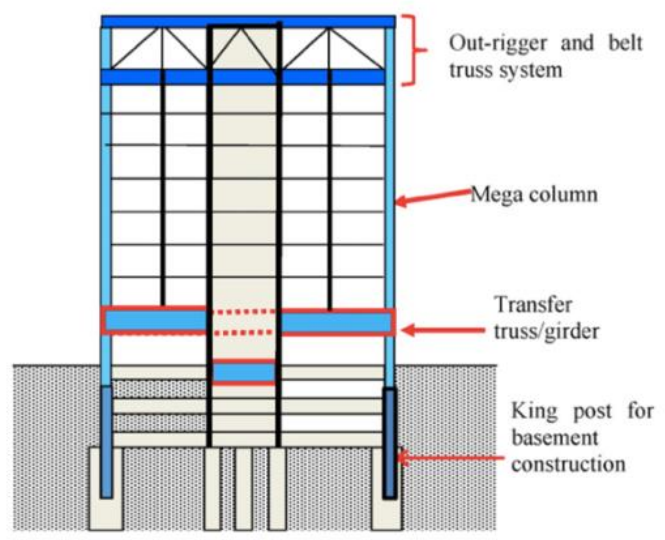

Figure 28. Super-frame model [1] 
A Super-frame model was made using E-tabs in lieu of this study to see the performance of the Composite UHPC filled steel tubes.

\subsubsection{Objective}

The main objective of this study was to assess the performance of UHPC filled steel tube columns when subjected to lateral loading. To have a comparison, four different types of sections were considered as listed above.

Figure 29 shows the 3-D elevation and plan of the Super-frame. All the dimensions shown in the plan are in meter, and only the exterior bay was analyzed.

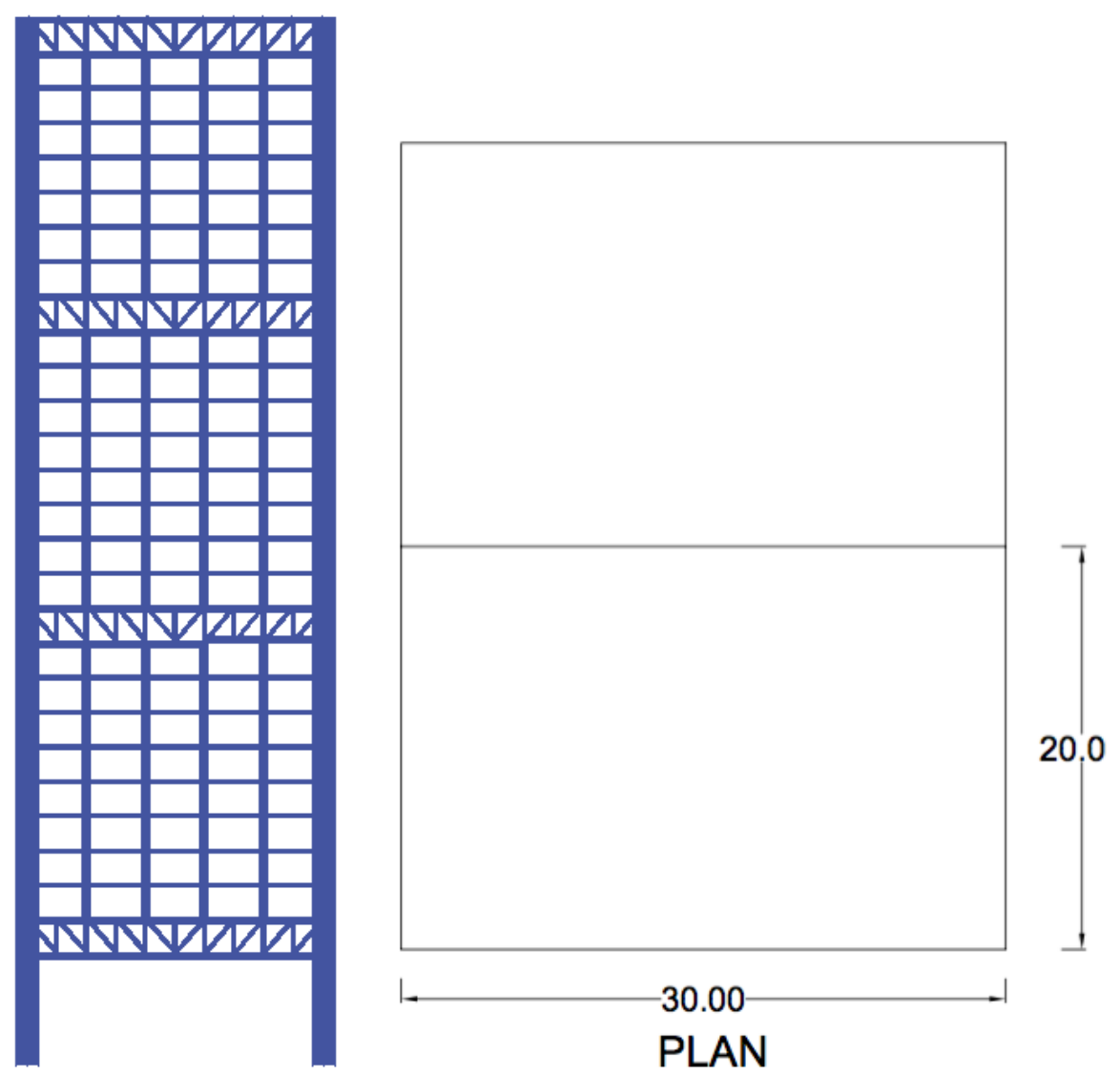

Figure 29. Super-frame Elevation and Plan (dimensions are in Meters)

\subsubsection{Assumptions}

A 30 story Super-frame building was considered to be built in Toronto area of total height $106 \mathrm{~m}$. 
$>$ The height of Mega Column was $28 \mathrm{~m}$ running between outrigger truss system provided at every $8^{\text {th }}$ story.

Ultra- High-Performance Concrete of $160 \mathrm{MPa}$ Strength was used.

The value of modulus of Elasticity used was $50000 \mathrm{MPa}$.

The design is based on the CSA Code, and all the wind load calculations were done according to NBCC.

All the supports are assumed to be fixed.

All the dimensions are in Metre.

Only one frame is analyzed.

The thickness of the slab was assumed as $250 \mathrm{~mm}$.

The building consists of 3 frames $20 \mathrm{~m}$ apart.

Only the central core of the frame was braced.

\subsubsection{Loading}

The live load was used according to NBCC and superimposed dead load was assumed for each floor. Table 10 shows the live load and superimposed dead loads used.

Table 10. Live load and superimposed dead load.

\begin{tabular}{|c|c|}
\hline LIVE LOADS & SUPERIMPOSED DEAD LOADS \\
\hline Floor $-1.9 \mathrm{Kpa}$ & Floor $-1.44 \mathrm{Kpa}$ \\
Roof $-1 \mathrm{Kpa}$ & Roof $-0.7 \mathrm{Kpa}$ \\
\hline
\end{tabular}

Factored live load on each floor $1.9 *$ span between frames $/ 2 * 1.5$

$$
1.9 * 10 * 1.5=28.5 \mathrm{KN} / \mathrm{m}
$$

Factored Live load on the roof $1 *$ span between frames $/ 2 * 1.5$ 


$$
1 * 10 * 1.5=15 \mathrm{KN} / \mathrm{m}
$$

Factored Dead load on each floor $1.45 *$ span between frames $/ 2 * 1.25$

$1.45 * 10 * 1.25=21.75 \mathrm{KN} / \mathrm{m}$

Factored Dead load on roof $0.7 * 10 * 1.25=8.75 \mathrm{KN} / \mathrm{m}$

Wind loading was used based on the NBCC. Figure 30 shows the wind load used in the study. The wind load is calculated and converted into point load that acts laterally on each floor.

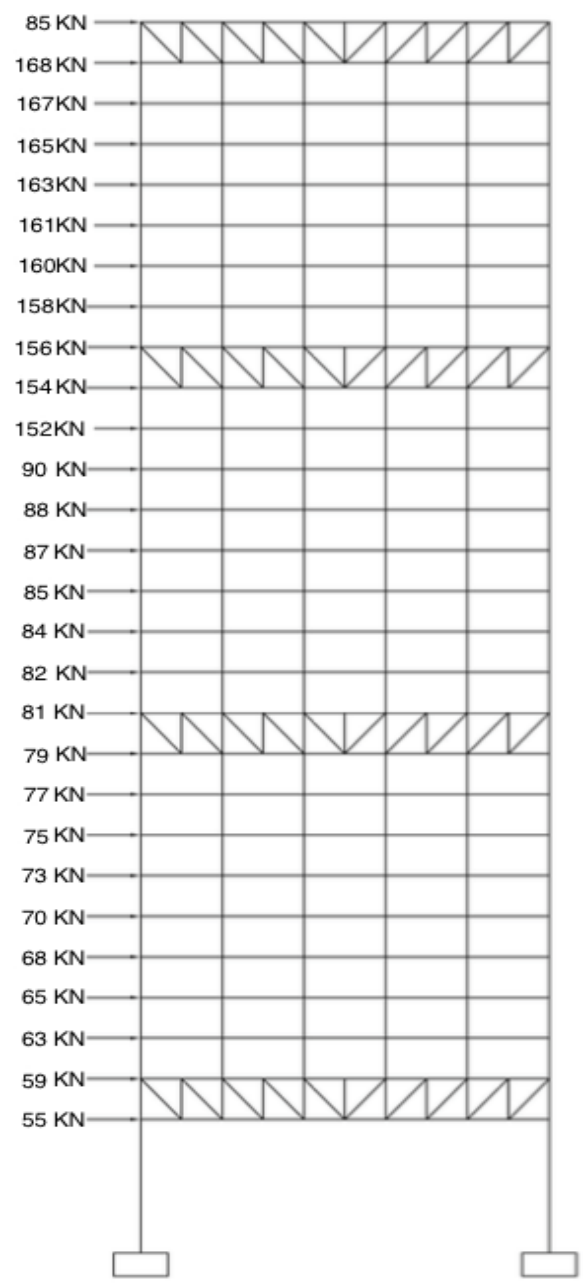

Figure 30. Wind load acting on the frame

\subsubsection{Load combination}




\subsubsection{Sections used.}

The preliminary sections were decided based on the total reaction at the base of the columns. Self-weight of slab / column $=[(24 * 0.25+1.5) * 28] * 1.25 * 7 * 10 * 15=220500 \mathrm{KN}$ Self-weight of truss was calculated by assuming a trial truss of deep sections. W40 X 397 as top and bottom cord members and HSS10 X 0.625 as vertical and diagonal members.

$$
\begin{array}{ll}
\text { W } 40 \times 397=590.7 \mathrm{Kg} / \mathrm{m} & =5.79 \mathrm{KN} / \mathrm{m} \\
\text { Factored self-weight } & =5.79 * 1.25=7.24 \mathrm{KN} / \mathrm{m} \\
\text { HSS } 10 \times 0.625 & =0.94 \mathrm{KN} / \mathrm{m} \\
\text { Factored self-weight } & =0.94 * 1.25=1.17 \mathrm{KN} / \mathrm{m} \\
\text { Total self-weight of Truss } & =7.24+1.17=8.4 \mathrm{KN} / \mathrm{m} \\
\text { Self-weight/ Column } & =8.4 * 10 * 15=1260 \mathrm{KN} \\
\text { Live load / Column } & =1.9 * 28 * 1.5 * 7 * 10 * 15=83790 \mathrm{KN} \\
\text { Net Reaction at the base of each column } & =220500+1260+83790=305550 \mathrm{KN}
\end{array}
$$

After calculation, the net reaction the section size for the columns was worked out according to Canadian code.

$$
P_{r}=0.8\left[\alpha_{1} \phi_{c} f_{c}^{\prime} A_{g}+\phi_{s} f_{y} A_{s t}\right]
$$

Assume $2400 \mathrm{~mm}$ diameter UHPC column with $2 \%$ reinforcement. Using equation (a) the capacity is calculated.

$$
A_{g}=\frac{\pi}{4} *(2400)^{2}=4521600 \mathrm{~mm}^{2}
$$




$$
A_{s t}=0.02 * 4521600=90432 \mathrm{~mm}^{2}
$$

Provide $40-50 \mathrm{M}$ bars, $\mathrm{A}_{\mathrm{st}}=100000 \mathrm{~m}^{2}$

Substituting above two equations in equation (a)

$$
P_{r}=0.8[0.8 * 0.65 * 160 * 4521600+0.85 * 400 * 90432]=325555.2 \mathrm{KN} .
$$

Since section capacity was greater than net reaction first trial section of $2400 \mathrm{~mm}$ circular column was used and then accordingly with the software analyzes the section sizes were revised. Table 11 Shows the revised sections used for the analysis.

Table 11. Sections for Super-frame

\begin{tabular}{|l|l|}
\hline Interior Beam & The hollow steel Tube section \\
& Depth $=550 \mathrm{~mm}$ \\
& Width $=450 \mathrm{~mm}$ \\
& Flange and web thickness $=30 \mathrm{~mm}$ \\
\hline Interior Columns & Hollow Steel Tube Section \\
& Depth $=950 \mathrm{~mm}$ \\
& Width $=950 \mathrm{~mm}$ \\
\hline Truss Top and Bottom cord members & Flange and Web thickness $=45 \mathrm{~mm}$ \\
& Steel Tubes Sections \\
& Depth $=800 \mathrm{~mm}$ \\
& Width $=800 \mathrm{~mm}$ \\
\hline Truss Vertical and Diagonal members & Flange and Web thickness $=40 \mathrm{~mm}$ \\
\hline & Steel Tube Section \\
& Depth $=550 \mathrm{~mm}$ \\
& Width $=500 \mathrm{~mm}$ \\
\hline
\end{tabular}




\begin{tabular}{|l|l|}
\hline Steel Mega Column & $1500 \mathrm{~mm}$ circular solid pipe \\
\hline UHPC Mega Column & $2500 \mathrm{~mm}$ \\
\hline Composite Column & $2400 \mathrm{~mm}$ hollow tube of $30 \mathrm{~mm}$ thickness \\
& filled with UHPC. \\
\hline Bracing & W 10 X 12 \\
\hline
\end{tabular}

After getting all the sections, the Super-frame was subjected to wind load for all different types of Mega Column sections, and its performance against lateral loading was assessed by calculating the lateral displacement of each story. Figure 31 shows the comparison of four systems. It can be seen from the curves that the composite system had the least lateral displacement and thus performs better than the other two systems. This system can prove a boon in saving millions of dollars by reducing the section sizes and material.

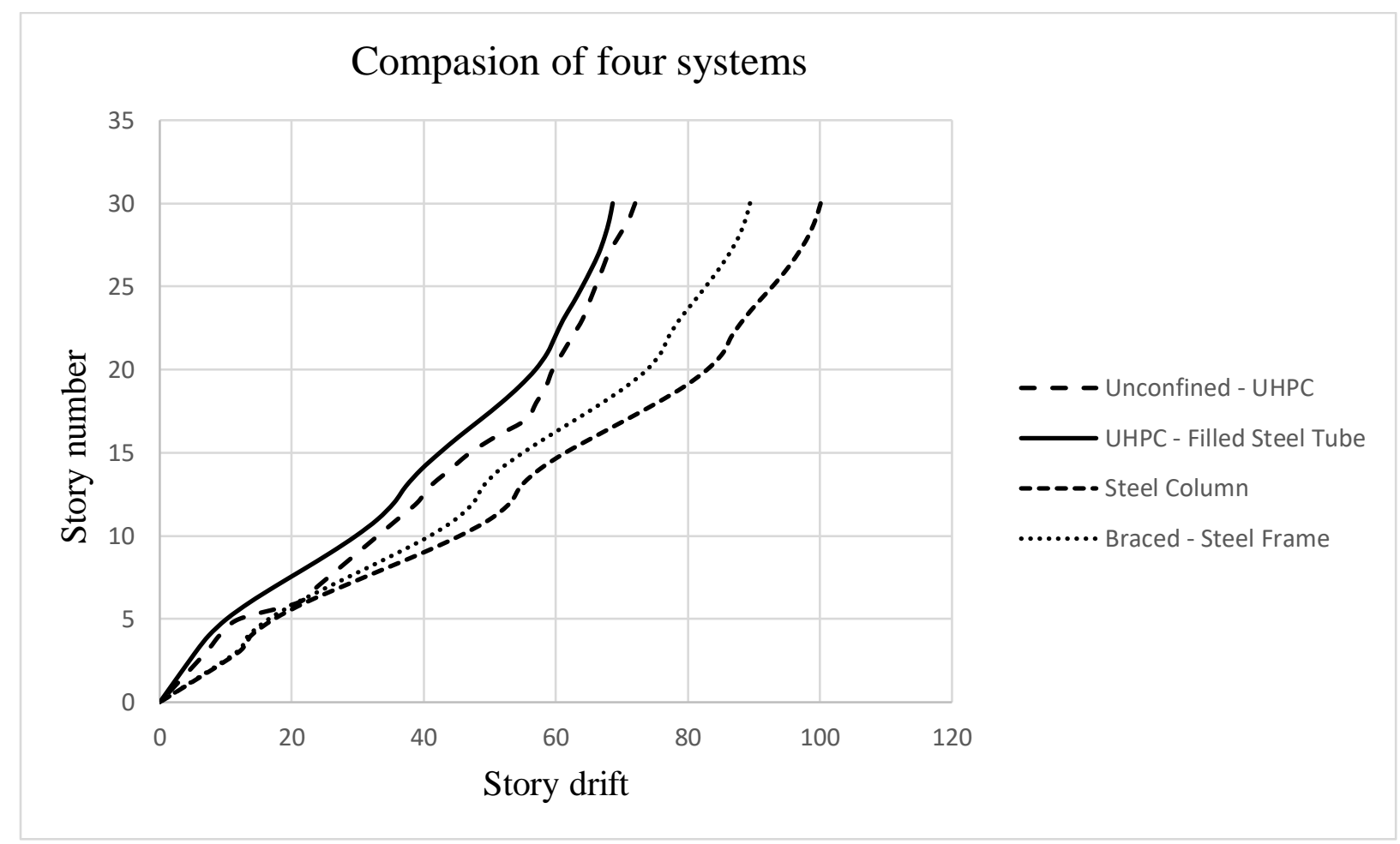

Figure 31. Comparison of four systems 


\subsection{Case Study 2 - Residential Building}

In this case study, a framed residential building was modeled on E-tabs to compare the lateral deflection of four systems having their exterior columns as:

Frame with hollow steel columns

Frame with hollow steel columns braced with $\mathrm{X}$ bracing

UHPC columns

Frame with hollow steel tubes filled with UHPC columns.

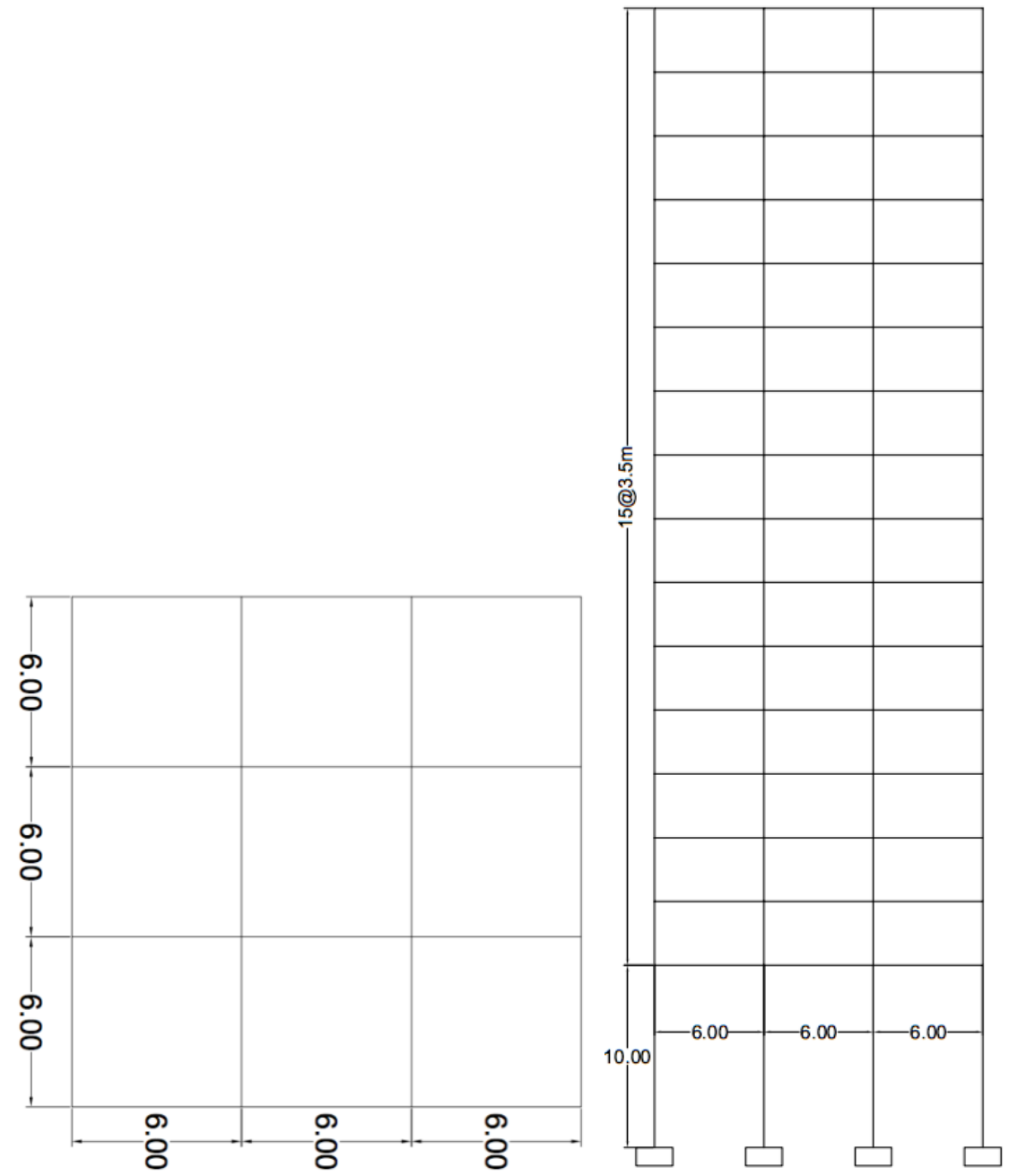

Figure 32. Building plan and Elevation (Meters)

\subsubsection{Assumptions}


$>$ Supports are fixed.

The connections of braces are pinned.

16 Story Residential building was considered with a base floor of $10 \mathrm{~m}$ long mega column and $3.5 \mathrm{~m}$ for other stories.

The total height of the building is $62.5 \mathrm{~m}$.

The building is considered in Toronto, and NBCC is used for wind load calculations.

E-tabs was used to find the displacements.

$150 \mathrm{MPa}$ Ultra-High-Performance Concrete was used for the model.

Only the central core is braced.

\subsubsection{Loading}

Table 12 shows the live load and superimposed dead loads used for the model.

Table 12 Live and Dead loads used [NBCC]

\begin{tabular}{|c|c|}
\hline LIVE LOADS & SUPERIMPOSED DEAD LOAD \\
\hline FLOOR $-1.9 \mathrm{KPa}$ & FLOOR $-1.44 \mathrm{KPa}$ (assumed) \\
ROOF $-1 \mathrm{KPa}$ & ROOF $-0.7 \mathrm{KPa}$ (assumed) \\
\hline
\end{tabular}

\subsubsection{Load Combination}

$>1.25 \mathrm{DL}+1.5 \mathrm{LL}$ was used to work out the section sizes.

$>1.25 \mathrm{DL}+1.05 \mathrm{LL}+1.05 \mathrm{WL}$ was used to calculate the lateral displacements of the building.

\subsubsection{Section Details}

Same procedure as for Case Study 1 was followed to determine the section sizes. Table 13 show sections used. 
Table 13 Section Sizes

\begin{tabular}{|c|c|c|c|c|}
\hline Member & Hollow & Braced Frame & COMPOSITE & UHPC \\
\hline COLUMNS & $\begin{array}{c}650 \mathrm{~mm} \text { diameter } \\
18 \mathrm{~mm} \text { thick }\end{array}$ & $\begin{array}{c}420 \mathrm{~mm} \\
\text { diameter } \\
14 \mathrm{~mm} \text { thick }\end{array}$ & $\begin{array}{c}650 \mathrm{~mm} \text { diameter } \\
18 \mathrm{~mm} \text { thick }\end{array}$ & $\begin{array}{c}700 \mathrm{~mm} \\
\text { diameter }\end{array}$ \\
\hline BEAMS & 370 X 525 (D X & $\begin{array}{c}370 \times 225 \\
\text { W) }\end{array}$ & $\begin{array}{c}400 \times 600 \\
13 \mathrm{~mm} \text { thick }\end{array}$ & $400 \times 550$ \\
\hline BRACES & None & W 5x16 & None & None \\
\hline
\end{tabular}
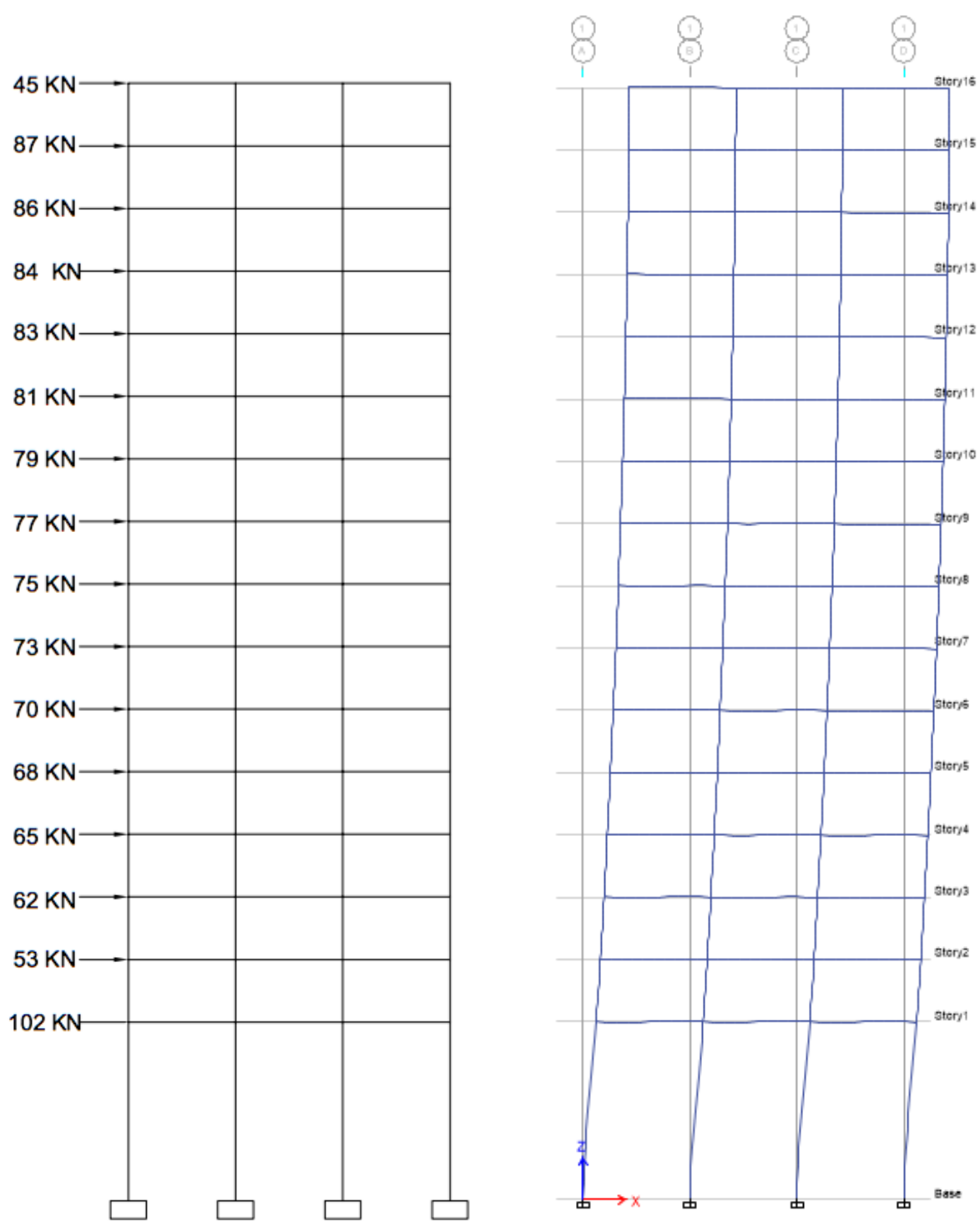

Figure 33. wind load (left), deformed frame (right) 
The lateral displacement of all the four systems obtained from the analysis was used in excel to develop comparison graph. Figure 34 shows the comparison of all the four systems analyzed in this study. The results show that for lower levels of building up to the $7^{\text {th }}$ floor the performance of the braced system was better than all but as the height increases the lateral displacement for braced system becomes more than composite column system. Overall the composite column system shows the least lateral displacement above $7^{\text {th }}$ floor and thus have superior performance than all other systems.

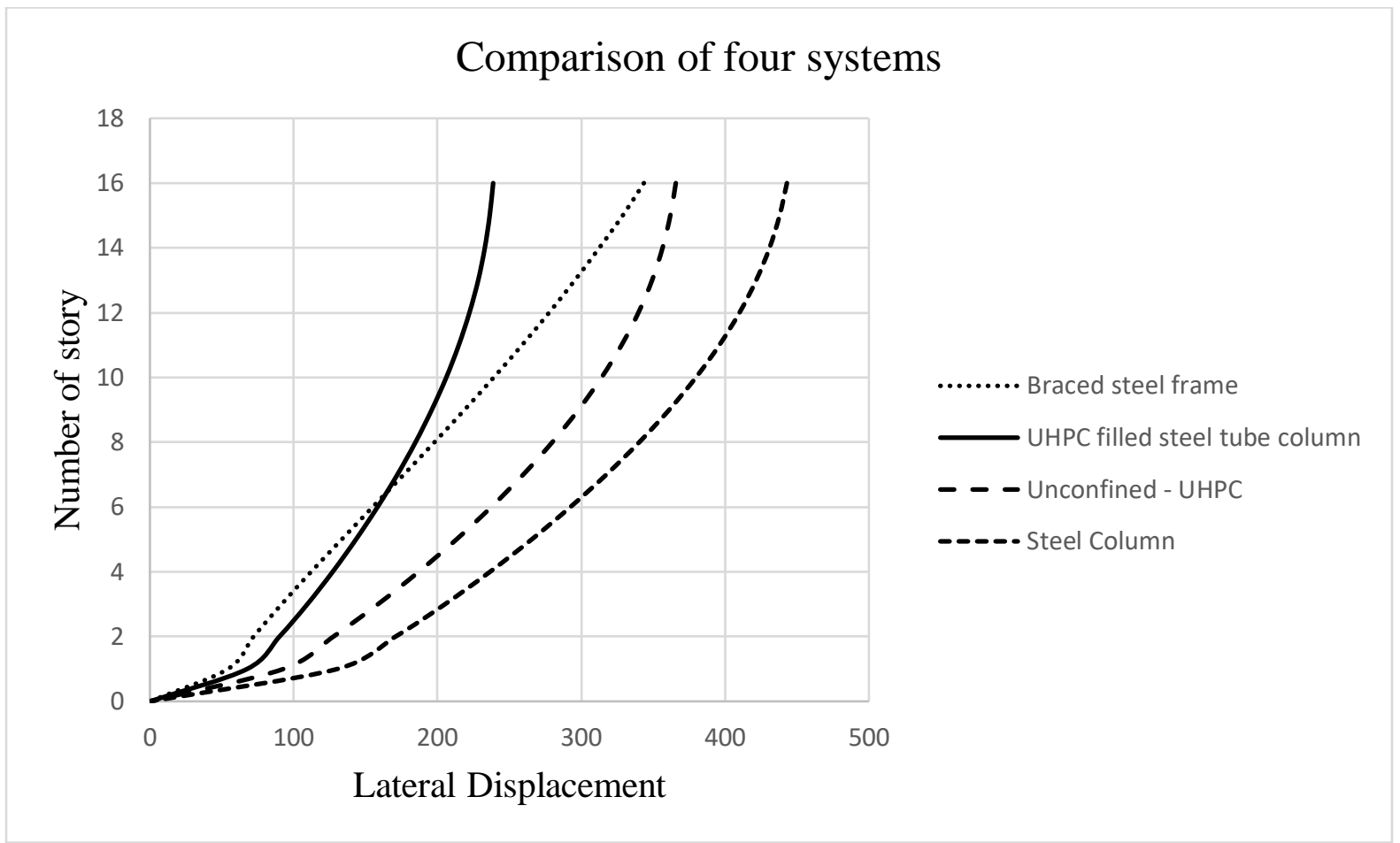

Figure 34. Comparison of four systems

\subsection{Discussion}

The numerical analysis study reflects that the performance of the composite sections in resisting the lateral loads in high rise building is best in comparison to other three conventional systems. Thus the use of composite sections for high rise construction has significant advantages and are beneficial for construction of mega columns known as Super-frame. 


\section{Chapter - 6}

\section{Discussion and Conclusion.}

\subsection{Summary}

In recent decades, Concrete filled steel tubes are widely used for the construction of high rise buildings. CFST has shown much-enhanced performance regarding structural behavior in comparison to conventional steel and concrete sections. The concrete core prevents the lateral deformation of steel, and the steel encasing improves the ductility of the concrete core. The use of steel tube acts as a permanent formwork and improves the strengthening, ductility, and stiffness of the composite section. However, traditional concrete cannot be used as infill material due to high shrinkage of traditional concrete that would lead to a de-bonding gap between the steel and concrete core, thus affecting the composite action. The use of UHPC as an infill material would reduce such drawbacks. UHPC offers much more enhanced mechanical properties, low shrinkage and creep characteristics. The dense microstructure of UHPC makes it more resistant to the attack of chemical and physical agents and thus improves the durability and lifespan of the structure. Low shrinkage of UHPC makes it good non-shrink grout material. UHPC permits the design of thinner concrete sections, this enhances the architectural beauty of the structures, and more random shaped structures can be built. However, still, there is a lack of data for design and advantages of such composite sections. The modern design code such as ACI and Canadian design code (CSA A23.3-14) do not cover the design of such composite sections as they do not take into account the effect of confinement of steel tube. However, the Eurocode 4 approach for the design of composite sections provides reliable results by taking into account the effect of confinement of steel tube.

A research investigation was conducted at the Department of Civil Engineering, Ryerson University to evaluate the performance of the composite section (UHPC filled circular steel 
tube column). Four long columns of height $2 \mathrm{~m}$ were tested in this study under compression loading machine. An analytical study using the EC 4 approach was conducted to develop the moment interaction diagram for the composite section. In addition to that, a numerical study was also conducted using ETABS, and different systems were modeled and studied regarding performance against the lateral loading.

\subsection{Conclusions}

As the results for confined UHPC and HPC could not be obtained in the experimental study, numerical and analytical study was conducted to study the performance of composite sections. The following sections summaries the conclusions from all the studies conducted.

\subsubsection{Experimental testing conclusions}

The experimental test results for unconfined UHPC and HPC show that UHPC specimen have enhanced load carrying and deformation capacity. The load carrying capacity of the UHPC column was much higher than HPC column, while axial deformation was lower than HPC at failure load.

\subsubsection{Analytical model calibration conclusion}

EC 4 approach was used to develop moment interaction curves for Confined UHPC and HPC specimens. As ACI and Canadian codes do not take into account the effects of confinement, they were not used in this study. The moment diagram shows that Confined UHPC specimen has more enhanced structural performance in comparison to the Confined HPC specimen.

\subsubsection{Numerical comparative study conclusions}

The numerical study comparing the performance of four different systems (ductile steel frame, ductile steel frame with bracing, ductile UHPC frame and UHPC filled composite) for high rise building ( height $>35 \mathrm{~m}$ ) shows that UHPC filled composite section had much-enhanced 
performance in resisting the lateral loads and showed least lateral deformation in comparison to all other systems.

\subsection{Future research}

Since the confined sections could not be tested, more of such long columns should be tested so that to have reliable data and to achieve at more reliable results. 


\section{Appendix- A}

\section{Eurocode 4 Simplified Method}

$$
\begin{aligned}
& \mathrm{E}_{\mathrm{cm}}=22\left[\frac{\eta * \mathrm{f}_{\mathrm{ck}}+8}{10}\right]^{0.3} \\
& \mathrm{E}=22\left[\frac{0.8 * 150+8}{10}\right]^{0.3}=47 \mathrm{GPa} \\
& I_{a}=\pi / 64\left[D^{4}-\left(D-2 * t_{\text {tube }}\right)^{4}\right. \\
& I_{a}=\pi / 64\left[(140.1)^{4}-(140.1-2 * 6.55)^{4}\right]=6124655 \mathrm{~mm}^{4} \\
& I_{c}=\pi / 64\left[D-2 * t_{\text {tube }}\right)^{4} \\
& I_{c}=\pi / 64\left[(140.1-2 * 6.55)^{4}\right]=12723194 \mathrm{~mm}^{4} \\
& \mathrm{t}_{\mathrm{s}}=\frac{\mathrm{A}_{\mathrm{st}}}{\pi(\mathrm{D}-2 * \text { cover })}=\frac{600}{\pi(140.1-2 * 13.5)}=1.69 \mathrm{~mm} \\
& \mathrm{D}_{\mathrm{s}}=\mathrm{D}-\left(2 * \text { cover }+\mathrm{t}_{\mathrm{s}}\right)=140.1-(2 * 13.5+1.69)=111.31 \mathrm{~mm} \\
& I_{a}=\pi / 64\left[D_{s}^{4}-\left(D_{s}-2 * t_{s}\right)^{4}\right. \\
& \mathrm{I}_{\mathrm{s}}=\pi / 64\left[(111.31)^{4}-(111.31-2 * 1.69)^{4}=860000 \mathrm{~mm}^{4}\right. \\
& (E I)_{\text {eff }}=E_{a} I_{a}+E_{s} I_{s}+0.6 E_{c m} I_{c} \\
& (\mathrm{EI})_{\mathrm{eff}}=200 * 6124655+200 * 860000+0.6 * 47 * 12723194 \\
& (\mathrm{EI})_{\mathrm{eff}}=1753.72 \times 10^{6} \mathrm{Nmm}^{2} \\
& \mathrm{~N}_{\mathrm{cr}}=\pi^{2} * \frac{(\mathrm{EI})_{\mathrm{eff}}}{\mathrm{L}_{\mathrm{eff}}{ }^{2}}=(3.14)^{2} * \frac{1753.72 \times 10^{6}}{(0.7 * 2000)}=8821.93 \mathrm{KN} \\
& N_{p l, R k}=A_{a} f_{y}+A_{c} f_{c k}+A_{s} f_{y} \\
& \mathrm{~N}_{\mathrm{pl}, \mathrm{Rk}}=2744.67 * 400+12641 * 150+600 * 400=3234.02 \mathrm{KN}
\end{aligned}
$$


$\lambda=\sqrt{\frac{N_{p l, R k}}{N_{c r}}}=\sqrt{3234.42 / 8821.93}=0.61<2.0[$ EC-4]

Hence OK

$$
\begin{aligned}
& \Phi=0.5\left[1+\alpha(\lambda-0.2)+\lambda^{2}\right] \\
& \Phi=0.5\left[1+0.34(0.61-0.2)+(0.61)^{2}\right]=0.75 \\
& \chi=\frac{1}{\Phi+\sqrt{\Phi^{2}-\lambda^{2}}} \\
& \chi=\frac{1}{0.75+\sqrt{(0.75)^{2}-(0.61)^{2}}}=0.84
\end{aligned}
$$

Point A, Pure Axial capacity

$$
\begin{aligned}
& \mathrm{N}_{\mathrm{pl}, \mathrm{Rd}}=\eta_{\mathrm{a}} \mathrm{A}_{\mathrm{a}} \mathrm{f}_{\mathrm{yd}}+\mathrm{A}_{\mathrm{c}} \mathrm{f}_{\mathrm{cd}}\left(1+\eta_{\mathrm{c}} \frac{\mathrm{t}_{\text {tube }} \mathrm{f}_{\mathrm{y}}}{\mathrm{d} \mathrm{f}_{\mathrm{cd}}}\right)+\mathrm{A}_{\mathrm{s}} \mathrm{f}_{\mathrm{sd}} \\
& \mathrm{N}_{\mathrm{pl}, \mathrm{Rk}}=0.25 * 2744.67 * 400+12661.27 * 150\left(1+\frac{4.9 * 6.55 * 400}{140.1 * 150}\right) \\
& \quad+600 * 400=3569.79 \mathrm{KN} \\
& \chi * \mathrm{~N}=0.84 * 3569.79=2998.62 \mathrm{KN} .
\end{aligned}
$$

Point $B$, Pure bending

$$
h_{n}=\frac{A_{c} f_{c d}}{2 D f_{c d}+4 t_{\text {tube }}\left(2 f_{y d}-f_{c d}\right)+4 t_{s}\left(2 f_{s d}-f_{c d}\right)}
$$




$$
\begin{aligned}
\mathrm{h}_{\mathrm{n}}= & \frac{12661.27 * 150}{2 * 140.1+4 * 6.55 *(2 * 400-150)+4 * 1.69 *(2 * 400-150)} \\
= & 29.93 \mathrm{~mm} \\
W_{p c}= & \frac{(d-2 * t)^{3}}{6} \\
W_{p c}= & (140.1-2 * 6.55)^{3} / 6=341.39 \mathrm{~cm}^{3} \\
W_{p c, n}= & \left(d-2 t_{t u b e}\right) * h_{n}{ }^{2} \\
W_{p c, n}= & (140.1-2 * 6.55) *(29.93)^{2}=113.77 \mathrm{~cm}^{3} \\
W_{p a}= & \frac{d^{3}}{6}-W_{p c} \\
W_{p a}= & \frac{140.1}{6}-341.39 \times 10^{3}=116.92 \mathrm{~cm}^{3} \\
W_{p a, n}= & d h^{2}{ }_{n}-W_{p c, n} \\
W_{p a, n}= & 140.1 *(29.93)^{2}-113.77 \times 10^{3}=11.73 \mathrm{~cm}^{3} \\
W_{p s, n}= & 2 t_{s} h^{2}{ }_{n} \\
W_{p s, n}= & 2 * 1.69 *(29.93)^{2}=3.03 \mathrm{~cm}^{3} \\
W_{p s}= & \frac{D_{s}{ }^{3}-\left(D_{s}-2 t_{s}\right)^{3}}{6} \\
\left.W_{p c}-W_{p c, n}\right) f_{c d} & (111.31)^{3}-(111.31-2 * 1.69)^{3} \\
6 &
\end{aligned}
$$




$$
\begin{array}{r}
M_{p l, R d}=(116.92-11.73) * 400+(20.31-3.03) * 400 \\
+0.5(341.30-113.77) 150=66.05 \mathrm{KNm}
\end{array}
$$

Point C, Prior to steel yielding

$$
\begin{aligned}
& N_{p m, R d}=A_{c} f_{c d}\left(1+\eta_{c} \frac{t f_{y}}{d f_{c d}}\right) \\
& N_{p m, R d}=12661.27 * 150\left(1+\frac{4.9 * 6.55 * 400}{140.1 * 150}\right)=3059.40 \mathrm{KN}
\end{aligned}
$$

Point D, Balanced Point

$$
\begin{aligned}
& M_{p l, R d}=W_{p a} * f_{y d}+W_{p s} * f_{s d}+0.5 * W_{p c} * f_{c d} \\
& M_{p l, R d}=116.92 * 400+20.31 * 400+0.5 * 341.39 * 150 \\
& =80.49 \mathrm{KNm}
\end{aligned}
$$

Same steps were followed for HPC. 


\section{References}

1 Liew JYR, Xiong M, Xiong D. Design of Concrete-Filled Tubular Beam-columns with High Strength Steel and Concrete. Structures. 2016; p. 213-226.

2 Jung Jun P, Su Tae K, Kyung Taek K, Sung Wook K. Influence of the ingredients on the compressive strength of UHPC as a fundamental study to optimize the mixing proportion. In Proceedings of the 2nd International Symposium on Ultra-High Performance Concrete, Kassel, Germany. 2008; p. 105-112.

3. Wille K, E.Naaman A, J.Parra-Montesinos G. Ultra-High Performance Concrete with Compressive Strength Exceeding $150 \mathrm{MPa}$ (22Ksi): A Simpler Way. ACI MATERIALS. $2011 \mathrm{Jan} / \mathrm{Feb} ; 108(1):$ p. 46-54.

4 A. B, Graybeal. CHARACTERIZATION OF THE BEHAVIOR OF ULTRA-HIGH PERFORMANCE CONCRETE. Ph.D. dissertation. Maryland University; 2005.

5 Dils J, Boel V, Schutter GD. Influence of cement type and mixing pressure on-air content, rheology and mechanical properties of UHPC. Construction and Building Materials. 2013 December; p. 455-463.

6 Viet Tue N, Ma J, Orgass M. Influence of addition method of superplasticizer on the properties of fresh UHPC. In Proceedings of the 2nd International Symposium on Ultra High-Performance Concrete, Kassel, Germany. 2008; p. 93-100.

7 Prem RP, H.Bharatkumar B, Murthy RA. Influence of curing regime and steel fibers on the mechanical properties of UHPC. Magazine of Concrete Research. 2015 February; 67(18): p. 988-1002.

8 Perry VH, Zakariasen D, Inc CL. First Use of Ultra-High Performance Concrete for an Innovative Train Station Canopy. Concrete Technology. 2004 August; 25(2): p. 1-2.

9 Shafieifar M, Farzad M, Azizinamini A. Experimental and numerical study on mechanical properties of Ultra High-Performance Concrete (UHPC). Construction and Building Materials. 2017 September; p. 402-411.

10 Wille K, Kim DJ, Naaman AE. Strain-hardening UHP-FRC with low fiber contents. Materials and Structures. 2011 April; 44(3): p. 583-598. 
11 Will K, Naaman AE, El-Tawil S, Parra-Montesinos GJ. Ultra-high performance concrete and fiber reinforced concrete: achieving strength and ductility without heat curing. Materials and Structures. 2012 March; 45(3): p. 309-324.

12 Lafarge. Lafarge North America. 2017. http://www.ductal-lafarge.com.

13 Li M, Zong Z, Liu L, Lou F. Experimental and numerical study on damage mechanism of CFDST bridge columns subjected to contact explosion. Engineering Structures. 2018; p. 265-276.

14 Othman H, Marzouk H. Impact Response of Ultra-High-Performance Reinforced Concrete Plates. ACI Structural Journal. 2016 Nov/Dec; 113(6): p. 1325-1334.

15 Othman H, Marzouk H. Dynamic identification of damage control characteristics of ultrahigh performance fiber reinforced concrete. Construction and Building Materials. 2017 December; 157(30): p. 899-908.

16 Vojvodic G, Hadl P, Tung DN, Tue VN. CIRCULAR UHPC-NSC COMPOSITE COLUMNS UNDER CONCENTRIC LOADING. Symposium on Ultra-High Performance Fiber-Reinforced Concrete, Montpellier, France. 2017 October;: p. 491-497.

17 Fehling E, An Le H. TEST ON CIRCULAR STEEL TUBE CONFINED UHPC AND UHPFRC COLUMNS UNDER AXIAL LOADING. Symposium on Ultra-High Performance Fiber-Reinforced Concrete, Montpellier, France. 2017 October; p. 499-507.

18 Hoang AL, Nguyen CV. Evaluation of axial strength in circular STCC columns using UHPC and UHPFRC. Journal of Construction Steel Research. 2019 February; 153: p. 533 549.

19 Liew JYR, Xiong DX. Ultra-High Strength Concrete Filled Composite Columns for MultiStorey Building Construction. SAGE journals. 2012 September; 15(9): p. 1487-1503.

20 El-Dieb A. Mechanical, durability and microstructural characteristics of ultra high-strength self-compacting concrete incorporating steel fibers. Materials and Design. 2009 December; 30(10): p. 4286-4292.

21 Magureanu C, Sosa 1, Negrutiu C, Heghes B. Mechanical Properties and Durability of Ultra-High-Performance Concrete. ACI MATERIALS JOURNAL. 2012 March/April; 109(2): p. 177-183. 
22 Guler S, Aydogan M, Copur A. Axial capacity and ductility of circular UHPC-filled steel tube columns. Magazine of Concrete Research. 2013 February; 65(15): p. 898-905.

23 Shin HO, Yoon YS, D. Cook W, Mitchell D. Axial Load Response of Ultra-High-Strength Concrete Columns and High-Strength Reinforcement. ACI STRUCTURAL JOURNAL. 2016 March/April; 113(2): p. 325-336.

24 Hilal Y. UHPC Infilled Circular Steel Tube Column Design. MEng. TORONTO: Ryerson University, Civil Engineering; 2018.

25 Abbas S, Nehdi ML, Saleem MA. Ultra-High Performance Concrete: Mechanical Performance, Durability, Sustainability and Implementation Challenges. International Journal of Concrete Structures and Materials. 2016 September; 10(3): p. 271-295.

26 JY Richard Liew MXX. Design guide for concrete filled tubular members with high strength materials, Singapore. 